\title{
Comprehensive Study of Phase Transformation in Age-Hardening of Mg- 3Nd-0.2Zn by Means of Scanning Transmission Electron Microscopy
}

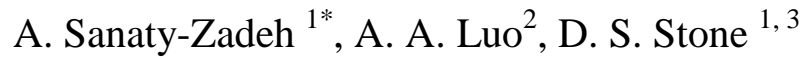 \\ ${ }^{1}$ Materials Science Program, University of Wisconsin-Madison, 1509 University Ave., Madison \\ WI 53706 \\ ${ }^{2}$ Department of Materials Science and Engineering, Department of Integrated Systems \\ Engineering, Ohio State University, Columbus, OH 43210 \\ ${ }^{3}$ Department of Materials Science and Engineering, University of Wisconsin-Madison, 1509 \\ University Ave., Madison WI 53706 \\ *(Corresponding Author; Tel: (414) 690-4956, Email: asanatyzadeh@nanoal.com)
}

\begin{abstract}
The effects of thermal history on precipitation behavior and precipitation kinetics in $\mathrm{Mg}-3 \mathrm{Nd}-$ $0.2 \mathrm{Zn}($ wt. \%) alloy were studied. The microstructure analysis of the aged alloys revealed the presence of new phases in the microstructure in addition to the old description: Super saturated solid solution $(S S S S) \rightarrow G$. P. zones $\rightarrow \beta^{\prime \prime} \rightarrow \beta^{\prime} / \beta_{1} \rightarrow \beta$, reported for $\mathrm{Mg}-\mathrm{Nd}$ system. In this regard, the sequence of precipitation for the studied alloy was identified as: Super saturated solid solution $($ SSSS $) \rightarrow$ Clusters of atoms $\rightarrow$ G. P. zones $(I, I I, I I I) \rightarrow \beta^{\prime} \rightarrow \beta_{2} \rightarrow \beta_{1} / \gamma^{\prime} \rightarrow \beta$. The formation of clusters of solute atoms in this system was confirmed by high angle annular dark field scanning transmission electron microscopy (HAADF-STEM) and atom probe tomography analysis. In addition, new metastable phases designated as G. P. zones (I, II, III) and $\beta_{2}$ were
\end{abstract}


identified in the microstructure of the aged alloys by means of high resolution HAADF-STEM. The $\beta_{2}$ phase was found to be a transition phase in transformation of $\beta$ ' to $\beta_{1}$. Furthermore, microstructure analysis revealed that the structure of $\beta_{l}$ phase is indeed a body centered tetragonal structure in spite of face centered cubic structure that has been reported for this phase in the literature.

Keywords: Magnesium alloys; Phase transformation; Age-hardening; Scanning electron transmission microscopy; Metastable phases

\section{Introduction}

Magnesium alloys have received considerable attention due to their low density and high specific strengths $[1,2]$. However, poor ductility of magnesium at room temperature due to its Hexagonal Closed-Packed (HCP) structure and low creep resistance and strength at elevated temperatures hinders its applications in critical structural components [1-3]. Modification of texture is reported to significantly improve the ductility of magnesium alloys $[2,3]$. This is achieved by alloying magnesium with rare-earth elements such as cerium $(\mathrm{Ce})$, gadolinium $(\mathrm{Gd})$, and neodymium (Nd) [4-7]. Addition of rare earth elements also has a significant effect on the hardness and creep resistance of Mg alloys both at room and elevated temperatures [8].

Among the rare earth elements $\mathrm{Nd}$ has relatively high solubility in $\operatorname{Mg}(\alpha)$ at the eutectic point $(0.55$ at. \%) and low solubility at room temperature $(\sim 100 \mathrm{ppm})$, which make it suitable for potential age hardening [8]. The strength of age-hardened Mg-Nd alloys can be further enhanced through solid solution strengthening by controlled addition of third element such as zinc $(\mathrm{Zn})[9$, 10-14]. Researches have shown that addition of $0.2 \mathrm{wt} . \% \mathrm{Zn}$ to $\mathrm{Mg}-3 \mathrm{Nd}$ wt. \% alloy improves 
the mechanical properties through mainly solid solution strengthening mechanism [8, 12-19]. However, higher amount of $\mathrm{Zn}$ than $0.5 \mathrm{wt}$ \% degrades the precipitation hardening effect from $\mathrm{Nd}$ due to the effect of zinc on the sequence and nature of precipitation [8].

The effect of $\mathrm{Zn}$ can be further recognized, as the precipitation sequence in $\mathrm{Mg}-3$ wt. \% $\mathrm{Nd}(\mathrm{Mg}$ $0.5 \mathrm{Nd}$ at. \%) alloy is drastically different from the ternary $\mathrm{Mg}-3 \mathrm{Nd}-1.3 \mathrm{Zn}$ wt.$\%$ (Mg- 0.5 Nd- $0.5 \mathrm{Zn}$ at. \%) alloy. The sequence in Mg-3 wt. \% Nd alloy is identified as: SSSS $\rightarrow$ G.P. zones $\rightarrow \beta^{\prime \prime} \rightarrow \beta^{\prime} / \beta_{1} \rightarrow \beta[7,8,20,21]$. This sequence is almost the same for rare earthcontaining magnesium alloys, although the kinetics of precipitation varies from one to another.

On the other hand, other researchers have identified that addition of $\mathrm{Zn}$ to Mg- 3 wt. \% Nd alloy alters the nature of precipitation such that for $\mathrm{Mg}-3 \mathrm{Nd}-0.5 \mathrm{Zn}$ wt.$\%(\mathrm{Mg}-0.5 \mathrm{Nd}-0.2 \mathrm{Zn}$ at. \%) and $\mathrm{Mg}-3 \mathrm{Nd}-1.3 \mathrm{Zn}$ at. $\%$ alloys, no $\beta$ series phase forms during decomposition of super saturated $\operatorname{Mg}(\alpha)$ solid solution. In this regard the sequence is identified as: SSSS $\rightarrow$ lowtemperature reaction $\rightarrow \gamma ” \rightarrow \gamma[8,9]$. Additionally, recent study on a newly designed $\mathrm{Mg}-3 \mathrm{Nd}-$ $0.2 \mathrm{Zn}$ wt. \% (Mg- $0.5 \mathrm{Nd}-0.1 \mathrm{Zn}$ at. \%) alloy showed that at $0.2 \mathrm{wt} . \% \mathrm{Zn}, \beta$ series and $\gamma^{\prime}$ phases co-precipitate in this alloy, however, $\gamma^{\prime}$ is sparsely distributed on grains. It is evident that the addition of high amount of $\mathrm{Zn}$ (higher than $0.5 \mathrm{wt} . \% \mathrm{Zn}$ ) completely changes the nature and sequence of precipitation from $\mathrm{Nd}$ enriched $\beta$ series to $\mathrm{Zn}$ enriched $\gamma$ series. In another word, the addition of high zinc content has a restricting effect on the precipitation of $\beta$ series, which has been shown to be the most effective precipitation hardening phase in rare-earth containing magnesium alloys $[8,22]$.

The structure of the G. P. zones in Mg-RE alloys has not been evaluated due to small size of these features and instrumentation limits; hence, information on this phase is limited. However, 
in a paper by Saito et al, it is reported to be the same as $\beta$ " [21]. The structure of $\beta$ " is determined as ordered D019 with $\mathrm{a}_{\beta}{ }^{\prime}=2 \mathrm{a}_{\mathrm{Mg}}$ and $\mathrm{c}_{\beta}{ }{ }=\mathrm{c}_{\mathrm{Mg}}$. According to the arrangement of atoms in the structure, the composition of $\beta$ " was determined as $\mathrm{Mg}_{3} \mathrm{Nd}[7,8,21]$. This phase forms on both prismatic planes type I and II ((1120) and (1010)) [8] and is fully coherent with the matrix. Similar structure has been reported for the $\beta$ "' in alloys containing Gd and Nd [21, 2326]. $\beta$ ' is fully coherent with the matrix and forms on prismatic planes type $\mathrm{I}(10 \overline{1} 0)$ [21, 23-25]. The lattice parameters for this phase have been determined from diffraction patterns and high resolution electron microscopy and the results are not consistent. In the research by Pike et al on $\operatorname{Mg}-3 \mathrm{Nd}$ (wt. \%) [7], the structure is determined as hexagonal with $\mathrm{a}_{\beta},=0.52 \mathrm{~nm}$ and $\mathrm{c}_{\beta},=1.3$ $\mathrm{nm}$. However, in recent researches on $\mathrm{Mg}-\mathrm{RE}$ ( $\mathrm{Gd}$, and $\mathrm{Nd}$ ) alloys, a base centered orthorhombic structure with lattice parameters $\mathrm{a}_{\beta},=0.642 \mathrm{~nm}, \mathrm{~b}_{\beta},=2.223 \mathrm{~nm}, \mathrm{c}_{\beta},=0.521 \mathrm{~nm}$ is reported for the $\beta$, phase. The composition of the $\beta$ ' phase based on $\mathrm{BCO}$ structure and proposed structural model for this phase is $\mathrm{Mg}_{14} \mathrm{RE}$ [23]. However, further STEM analysis which was performed later on Mg-Gd alloy showed a slightly different arrangement of solute atoms in $\beta^{\prime}$ [25]. The difference was the presence of an extra layer of solute atoms in $Z=1 / 2$ layer and at the same positions as $\mathrm{Z}=0$ layer. Based on the new arrangement, the lattice parameter $\mathrm{b}$ is determined to be $\mathrm{b}_{\beta}=1.11$ $\mathrm{nm}$. In addition, this arrangement of atoms results in a composition of $\mathrm{Mg}_{7} \mathrm{RE}$ that is closer to the composition reported for $\beta^{\prime}$ from atom probe tomography analysis [23].

The $\beta_{1}$ precipitates are formed on prismatic planes (1010). The structure of this phase was determined from HREM and diffraction patterns to be FCC with $\mathrm{a}_{\beta 1}=0.744 \mathrm{~nm}$. $\beta_{1}$ precipitates are semi coherent with the matrix. The composition of this phase is reported to be $\mathrm{Mg}_{3} \mathrm{Nd}$ [20].

The final precipitate in the sequence of precipitation is the equilibrium $\beta$ phase. Similar to $\beta$, different structure and lattice parameters have been reported for this phase. In a research by Pike 
et al, this phase was determined as a base centered tetragonal lattice with $\mathrm{a}_{\beta}=1.031 \mathrm{~nm}$ and $\mathrm{c}_{\beta}=0.593 \mathrm{~nm}$. The composition of $\beta$ was also determined to be $\mathrm{Mg}_{12} \mathrm{Nd}$ [7]. However, in some research conducted on Mg-RE alloys [8, 20], a FCC structure with composition of $\mathrm{Mg}_{5} \mathrm{RE}$ has been reported with $\mathrm{a}=2.223 \mathrm{~nm}$.

In terms of $\gamma$ series, there are two different reports on the structure of $\gamma$ ” phase. In the TEM study on $\mathrm{Mg}-2.8 \mathrm{Nd}-1.3 \mathrm{Zn}$ wt. $\%$, the lattice parameter for $\gamma^{\prime \prime}$ is reported to be an ordered hexagonal closed packed with $\mathrm{a}_{\gamma}{ }^{\prime \prime}=\sqrt{ } 3 \mathrm{a}_{\mathrm{Mg}} ; \mathrm{c}_{\gamma}{ }^{\prime}=3 \mathrm{c}_{\mathrm{Mg}}[9]$. However, TEM and STEM analysis on a Mg-1Gd$0.4 \mathrm{Zn}-0.2 \mathrm{Zr}$ (at. \%) showed the same lattice structure but with $\mathrm{c}_{\gamma},=0.444 \mathrm{~nm}$. Also the atom probe tomography (APT) investigation showed a composition of $\mathrm{Mg}-15 \mathrm{Gd}-15 \mathrm{Zn}$ (at. \%) for this phase. $\gamma$ ” forms as plates on basal planes with a thickness of a single unit cell and aspect ratio of 60:1. The orientation relationship between $\gamma^{\prime \prime}$ and matrix is such that $(0001)_{\gamma}, / /(0001)_{\mathrm{Mg}}$ and $[10 \overline{1} 0]_{\gamma}, / /[2 \overline{11} 0]_{\mathrm{Mg}}[27]$.

$\gamma^{\prime}$ has been reported in Mg-Zn-RE alloys containing $\mathrm{Gd}$ and $\mathrm{Nd}[8,27]$ and has a disordered HCP structure with $\mathrm{a}_{\gamma^{\prime}}=0.321 \mathrm{~nm}$ and $\mathrm{c}_{\gamma^{\prime}}=0.781 \mathrm{~nm}$. For Mg-Gd-Zn, the closely packed planes in $\gamma^{\prime}$ have ${ }^{\cdots} \mathrm{ABCABC}^{\cdots}$ stacking sequence with $\mathrm{Zn}$ and $\mathrm{Gd}$ atoms in $\mathrm{B}$ and $\mathrm{C}$ planes. The composition of $\gamma^{\prime}$ has been reported to be the same as $\gamma^{\prime \prime}$. This phase also forms as plates on basal planes with a thickness of a unit cell height and very large aspect ratio. The orientation relationship between $\gamma^{\prime}$ and matrix is such that $(0001)_{\gamma^{\prime \prime}} / /(0001)_{\mathrm{Mg}}$ and $[21 \overline{1} 0]_{\gamma^{\prime \prime}} / /[2 \overline{11} 0]_{\mathrm{Mg}}$ [27]. The thickness of this phase does not change throughout the whole aging process in such way that it remains under $1 \mathrm{~nm}$ for prolonged aging times [27]. The last phase in this sequence is the equilibrium phase $\gamma$. This phase has an FCC structure similar to $\beta$ with $\mathrm{a}_{\gamma}=0.744 \mathrm{~nm}$. The structure and the lattice parameter of this phase are similar to the ones reported for $\beta_{1}$, however, the high amount of $\mathrm{Zn}$ and orientation with respect to the matrix are what make this phase 
different from $\beta_{1}$ [27].

As was noticed in the above discussion, there is no consistency on the structure of the intermediate phases reported for the Mg-Nd-Zn system. In addition, there is limited information on the precipitates that form during early stages of aging (i.e. G. P. zones). Furthermore, the nature and sequence of precipitation strongly depend on the composition of the alloy and varies by the amount of neodymium and zinc in the system and $\mathrm{Nd} / \mathrm{Zn}$ concentration ratio. Therefore, in this research, it is aimed to conduct a systematic study of the microstructure of $\mathrm{Mg}-3 \mathrm{Nd}-0.2 \mathrm{Zn}$ wt. \% alloy. Cs corrected atomic resolution HAADF-STEM technique and APT techniques were employed to explore the structure of the precipitates at different stages of precipitation and their relative compositions.

\section{Experimental}

The as-cast ingot of Mg-3Nd-0.2Zn-0.46Zr wt. \% (commercially known as NZ30K) was prepared by mixing of pure $\mathrm{Mg}, \mathrm{Zn}, \mathrm{Zr}$, and $\mathrm{Mg}-20 \mathrm{wt} . \% \mathrm{Nd}$ master alloy in a $200 \mathrm{lb}$ steel crucible under a protective gas mixture of $\mathrm{SF}_{6} / \mathrm{CO}_{2}$ and cast into a steel mold preheated to $200^{\circ} \mathrm{C}$. The alloy melt was degassed by bubbling pure Argon for about $20 \mathrm{~min}$ at $740{ }^{\circ} \mathrm{C}$, following which, the slag was removed prior to casting. The dimensions of the cast ingots were $15 \times 10 \times 3 \mathrm{~cm}^{3}$.

Samples with dimensions $10 \times 10 \times 5 \mathrm{~mm}^{3}$ were cut from the ingot, polished, and cleaned in ethanol. The samples were then wrapped in tantalum foil (to prevent reaction between the samples and the glass tube) and quickly encapsulated in glass tubes under helium atmosphere to prevent oxidation. Solution treatment of samples was performed at $540{ }^{\circ} \mathrm{C}$ for $5 \mathrm{hr}$ in a horizontal tube furnace followed by quenching in water at room temperature. Solution-treated alloys were 
polished after quenching to remove the oxide layer from the surface, cleaned with ethanol, and placed in an oil bath at $200{ }^{\circ} \mathrm{C}$ for different lengths of time between $30 \mathrm{~min}$ and $64 \mathrm{hr}$. After designated aging times, samples were taken out of the bath and cooled down in air. Aged samples were mounted on AFM specimen discs and glued down to a stainless steel cylinder for hardness measurements. They were then grinded and polished using diamond polishing laps from 15 micron down to 0.1 micron. The polished samples were cleaned with ethanol and dried in air.

For each sample with specific heat treatment condition, 10-15 indents were performed randomly on the surface of the sample and the average was reported as the hardness. Error bars were calculated based on standard deviation of the hardness measurements on each sample. The wedge TEM samples were prepared using Allied Multiprep machine by using diamond lapping films with different grid sizes from $10 \mu \mathrm{m}$ down to $0.1 \mu \mathrm{m}$. The wedge samples were further thinned by ion-milling.

Transmission electron microscopy and high resolution electron microscopy were used to study the microstructure and precipitation evolution in the heat treated alloys. A Philips CM200 operating at $200 \mathrm{kV}$ with a resolution of about $0.18 \mathrm{~nm}$ and FEG-Tecnai-TF30 operating at 300 $\mathrm{kV}$ with a resolution of about $0.19 \mathrm{~nm}$ were used for TEM and high resolution purpose. Cs corrected HAADF-STEM was utilized to study the microstructure of the aged samples and to identify the metastable phases that evolve during aging, specifically at early stages of precipitation. Subsequently, the structure of these phases were examined and constructed. STEM analyses were conducted on a TITAN microscope operating at $200 \mathrm{kV}$. The Cs corrector on this microscope allows achieving resolution of about $0.07 \mathrm{~nm}$. Acquired images were analyzed using TIA and Gatan digital micrograph software. The thickness of the samples was measured by 
electron energy loss spectroscopy (EELS) on regions where microstructure was analyzed. For each region three EELS runs were performed and the average thickness value was used. The absolute thickness values were extracted by measuring the beam convergence angle and EELS semi collection angle [28]. For calculating the number density of the second phase in Mg matrix, at least three images were analyzed and the average of all values was reported as the number density of clusters. The number density of clusters or precipitates in each image was obtained by dividing the number of counts by the volume (image size times the thickness) of the region $\left(\right.$ counts $/ \mathrm{m}^{3}$ ). The standard error (SE) was calculated and reported based on the standard deviation (SD) of the three measurements $(S E=2 \times S D / \sqrt{3})$.

Atom probe tomography (APT) technique was employed to analyze the composition of metastable phases evolved in aged samples. APT analyses were performed on a LEAP 3000X HR (Cameca, Madison, WI). Voltage pulse method was used with a pulse fraction of $20 \%$, evaporation rate of $0.5 \%$ and pulse repetition of $160 \mathrm{~Hz}$ at $30 \mathrm{~K}$. Needle shaped samples were made using a Zeiss focused ion beam. Data reconstruction for three-dimensional visualization was conducted by means of the Cameca commercial software IVAS ${ }^{\mathrm{TM}}$.

\section{Results}

The results of the hardness measurements on samples aged at $200^{\circ} \mathrm{C}$ for different length of time are presented in Fig. 1. It is noticed that the peak-aged condition for this alloy at $200^{\circ} \mathrm{C}$ occurs at aging times between 4-8 hours. This is consistent with the trend reported previously for the same alloy and implies fast precipitation kinetics at this temperature [1, 8]. To better understand the correlation between the hardness variations and evolution of microstructure during aging, three samples, aged at $200^{\circ} \mathrm{C}$, were chosen for STEM analysis; the $2 \mathrm{hr}$ aged sample (under-aged 
condition), the $8 \mathrm{hr}$ aged sample (peak-aged condition), and the $64 \mathrm{hr}$ sample (over-aged condition). The microstructure observations are summarized as follows.

\subsection{Under-aged condition}

Fig. 2 shows a low magnification HAADF-STEM image of the sample aged at $200^{\circ} \mathrm{C}$ for $2 \mathrm{hr}$ with the beam parallel to [0001] direction. The presence of precipitates (as bright phase) is evident on both types of prismatic planes. This orientation relationship with the matrix is signature of $\beta$ series precipitates. Although Fig. 2 does not show apparent difference between the present phases in the microstructure, higher magnification images revealed the presence of four distinct types of metastable phases under this aging condition. The detected phases are presented and analyzed in detail as follows.

\section{First type}

Fig. 3 shows high resolution HAADF-STEM images and corresponding models of the $2 \mathrm{hr}$ aged alloy at $200^{\circ} \mathrm{C}$ from three zone axes [0001], [12 10$]$ and [10 10$]$. The high resolution images were modeled to obtain the position of the solute atoms in the matrix and consequently the structure of the first type phase. In the modeled images, $\mathrm{Mg}$ atoms in layer $\mathrm{Z}=0$ and $\mathrm{Z}=1 / 2$ are shown with small yellow and red spheres and $\mathrm{Nd}$ atoms in layer $\mathrm{Z}=0$ and $\mathrm{Z}=1 / 2$ are displayed with larger blue and purple spheres. As seen in Fig. 3. (a), this phase has a discontinuous ordered structure along prismatic directions. In addition, no periodic arrangement of atoms in a wide range in $\{0001\}$ planes is seen for this phase throughout the matrix.

The arrangement of atoms in this phase range from 1 atomic column component to a series of 2 , 
3 , and 4 atom columns components. The position of solute atoms in components with more than one atomic column is such that they occupy the second nearest neighbor in the matrix on prismatic planes. The components containing 3 and 4 atom columns have a D019 arrangement (shown in Fig. 3 (b) inside the dashed circle) with $0.37 \mathrm{~nm}$ intervals between atom columns, as reconstructed in the model structure in Fig. 3 (b). The shape of these components is obtained by replacement of $\mathrm{Nd}$ atoms with $\mathrm{Mg}$ atoms in $\mathrm{HCP}$ lattice positions in the first and second layer. The arrangement of the components varies in the chain from all 3 to a combination of $1,2,3$, and 4 atom columns components. However, three main combinations were found as shown in Fig. 3 (b). These combinations include all three (A), 3-3-3-4-4 (B), and 4-4-4-2 (C). The atomic distance between repeating components is different in each type of combination.

As seen in Fig. 3 (a) and (b), this phase does not fully develop a unit cell of D019 and was found only in short range order. Therefore, considering the size and ordered structure of these precipitates, it is logical to refer to them as G. P. I zones or pre- $\beta$ " precipitates. G. P. I zones has not been reported previously for the Mg-Nd-Zn system.

For A and B type chains, the distance between repeating three atom columns components is 1.6 $\mathrm{nm}\left(5 \times \mathrm{a}_{0}\right)$. In addition, the distance between 4 atom column components in B type chain reduces to $850 \mathrm{pm}$. In C- type chain, the distances between $4-4$ combinations varies to 550 and $850 \mathrm{pm}$ and for $4-2$ combination, this distance is $550 \mathrm{pm}$. It is noteworthy to mention that the A and B type precipitates (containing 3 atom columns components) lie on prismatic planes type I $(\{10 \overline{1} 0\})$ where type $C$ with even number of atom column components lie on prismatic planes type II $(\{1 \overline{2} 10\})$.

Fig. 3 (c) and (e) reveal that G. P. I zone is elongated along $\mathrm{z}$ direction in about 10- $20 \mathrm{~nm}$. The periodic arrangement of the atoms is the same as $\mathrm{Mg}$ lattice; hence the lattice parameter in $\mathrm{Z}$ 
direction equals the one for $\mathrm{Mg}$ lattice. Since this phase is spread in just two directions, it can be referred to as plate-like precipitates on prismatic planes.

\section{Second type}

The FFT image taken from the region containing second type precipitate showed a diffraction pattern similar to base centered orthorhombic structure (Fig. 4 (a)). BCO has been reported for the metastable $\beta$ ' phase in rare earth containing magnesium alloys [8, 23, 24, 27, 29-31]. The high resolution HAADF-STEM images taken from this phase and corresponding models are shown in Fig. 4 (a)-(f). In the image taken with beam parallel to [0001] direction (Fig. 4 (a)), an array of zigzag chains is observed that are $1.1 \mathrm{~nm}$ apart from each other. The positions of atoms inside the chains are similar to 4 atom column components observed in G. P. zones. The zigzag chains are lying on prismatic planes type I ( $\{10 \overline{1} 0\})$ while the precipitate is extended along prismatic planes type II $(\{1 \overline{2} 10\})$. These precipitates are about $2 \mathrm{~nm}$ thick and $10-20 \mathrm{~nm}$ long on basal planes. The orientation relationship with the matrix can be written as $(10 \overline{10})_{\mathrm{Mg}} / /(010)_{\beta}$, and $(1 \overline{2} 10)_{\mathrm{Mg}} / /(100)_{\beta}$. However, the images taken with beam parallel to prismatic directions (i.e. [12 10$]$ and [10 $\overline{1} 0])$ show an extension of about $10-20 \mathrm{~nm}$ in $\mathrm{z}$ direction. Therefore, similar to first type, these precipitates have a plate-like shape. In addition, the lattice parameters measured for this type of precipitate are: $\mathrm{a}_{\beta}=0.64 \mathrm{~nm}, \mathrm{~b}_{\beta}=1.1 \mathrm{~nm}, \mathrm{c}_{\beta}=0.52 \mathrm{~nm}$. The arrangement of chains in the matrix as seen in Fig. 4 (a)-(f) creates an orthorhombic structure. As was mentioned earlier, the orthorhombic structure is a signature of $\beta$ ' precipitates in $\mathrm{Mg}-\mathrm{RE}$ alloys and therefore the second type precipitate observed in this study is referred to as $\beta$ '.

A closer examination of the microstructure, as evident from Fig. 5, showed that $\beta$ ' indeed exists as single unit cells in the matrix. Although it is expected that $\beta$ ' forms through transformation of 
the G. P. I zones or $\beta$ " phase, our observations revealed independent formation of $\beta$ ' unit cell on prismatic planes $\{1 \overline{2} 10\}$. On the other hand, the size and ordered structure of this components and their uniform presence in the matrix is consistent with formation of G. P. zones. Therefore, to distinguish with $\beta^{\prime}$ precipitates this phase is designated as G. P. II zones or pre- $\beta$ '.

\section{Third type}

The third type precipitate was detected with a uniform distribution in the matrix. Fig. 6 (a) represents a high resolution HAADF-STEM image of the matrix containing this phase and the corresponding FFT image. The corresponding model for Fig. 6 (a) is also shown in Fig. 6 (b). The orientation and arrangement of spots in the pattern is the same as orthorhombic structure and the one observed for $\beta$ '. However, the spots at $1 / 2\{10 \overline{1} 0\}$ are no longer visible.

According to the images obtained, the size of this phase is on the order of $5 \mathrm{~nm}$ long and $2 \mathrm{~nm}$ thick. In addition, the lattice structure of this phase was found to be an orthorhombic structure, similar to $\beta$ '. The lattice parameters for this phase are measured as $\mathrm{a}_{p p t}=0.64 \mathrm{~nm}, \mathrm{~b}_{p p t}=0.56 \mathrm{~nm}$, $\mathrm{c}_{p p t}=0.52 \mathrm{~nm}$. From STEM images, the orientation relationship of this phase with the matrix was obtained as $(10 \overline{1} 0)_{M g} / /(010)_{p p t}$ and $(1 \overline{2} 10)_{M g} / /(100)_{p p t}$. This phase has not been reported previously in Mg-RE alloys. Therefore, to distinguish with other phases, the third type phase was designated as $\beta_{2}$.

Analysis of the microstructure showed that similar to $\beta$ ' phase, $\beta_{2}$ also forms independently as single unit cells in the matrix (See Fig. 7). Microstructure observation showed that this phase is formed by a combination of: i) hexagon arrangement of atoms (shown with blue arrow) and cross shape (shown with red arrow heads) and ii) all cross shape. The former combination 
appears in the form of hexagon-cross, and hexagon-cross-cross as indicated by 1 and 2 in Fig. 7 (a)-(c), respectively. On the other hand, the latter combination comes in the form of cross pairs, indicated by 3 in Fig. 7 (b) and (c). If the combination contains only one cross shape, the precipitate lies on prismatic planes type II $(\{1 \overline{2} 10\})$ where in the case of combination with two cross shape, the precipitate form on prismatic planes type $I(\{10 \overline{1} 0\})$. The interesting point is that in either combination of hexagon-cross-cross or cross-cross, there is a $90^{\circ}$ rotation between the crosses which creates the orthorhombic arrangement of atoms. Similar to first type precipitate, the cross shape arrangement of atoms does not create a complete unit cell; however, it appears as a short range ordered structure in the microstructure. Therefore, to distinguish with the long-range ordered $\beta_{2}$ phase, this phase was designated as G. P. III zones or pre- $\beta_{2}$.

\section{Fourth type}

The FFT pattern taken from the region containing the fourth type phase (Fig. 8 (a)) showed similar pattern to $\beta_{1}$ precipitate. Further examination of the FFT pattern indicates that the spots from the precipitate do not fall at the same position as for $\mathrm{Mg}$ which indicates that this phase is not fully coherent with the matrix in all directions.

Fig. 8 (a)-(f) present high resolution HAADF-STEM images and corresponding models from the fourth type phase with beam parallel to basal and prismatic directions. It is evident that this phase precipitates on prismatic plane type I $(\{10 \overline{1} 0\})$. Examination of the images taken from

three zone axes (Fig. 8 (a)-(f)) revealed a similar atomic arrangement to $\beta_{1}$ in Mg-RE alloys. The structure of $\beta_{1}$ is reported to be FCC with $\mathrm{a}=0.74 \mathrm{~nm}[8,20]$.

As seen from Fig. 8 (a) and (b), this phase is coherent along [10 10$]$ direction and the distance 
between atomic planes in this direction is measured as $0.52 \mathrm{~nm}$, close to $2 \times d_{10 \overline{1} 0}$. However, in the $[1 \overline{2} 10]$ direction at the interface, there is a slight difference between the distance of atomic planes $(0.37 \mathrm{~nm}$ for the precipitate atomic planes vs. $0.32 \mathrm{~nm}$ for $\mathrm{Mg}$ atomic planes $)$ which eventually results in loss of coherency as the precipitate grows.

\section{Clustering of atoms}

Although no evidence of clustering of atoms was found in the literature for the $\mathrm{Mg}-\mathrm{Nd}-\mathrm{Zn}$ system, HAADF-STEM images showed a noticeable concentration of bright spots in some regions of the matrix. Fig. 9 (a) - (c) show the presence of these spots in the micrographs taken from three zone axes. These spots usually appeared as a group of brighter atom columns with about $1 \mathrm{~nm}$ or less in diameter and a lower contrast than identified phases. Since the micrographs from different zone axes show the same size and morphology for these spots and also no specific structure or ordering could be found, these features should be in the form of a congregate or clusters of atoms in the microstructure. The concentration of the clusters varies in different regions of the microstructure. The number density of the detected clusters was measured as $95.6 \pm 33 \times 10^{-5} \mathrm{~nm}^{-3}$. Additionally, we performed atom probe tomography analysis on the sample aged at $200^{\circ} \mathrm{C}$ for $2 \mathrm{hr}$. Fig. 10 shows the APT reconstruction and elemental maps of the alloying elements in the $2 \mathrm{hr}$ aged sample. Data analysis of clustering showed that a concentration of clusters of $\mathrm{Nd}-\mathrm{Zn}$ exists in the matrix with less than $1 \mathrm{~nm}$ diameter. A number density of 113.2 $\pm 27.6 \times 10^{-5} \mathrm{~nm}^{-3}$ was obtained for Nd-Zn clusters with diameter less than $1 \mathrm{~nm}$ which is in close agreement with the value obtained from HAADF-STEM images. 


\subsection{Peak-aged condition}

As was seen earlier, the peak-aged condition for the studied system occurs at aging times around $8 \mathrm{hr}$ for the aging temperature of $200{ }^{\circ} \mathrm{C}$. The microstructure of the sample at this aging condition was studied by means of STEM and the results are shown in Fig. 11. As it is evident, a uniform distribution of the precipitates is visible in the matrix.

In this aging condition, the length of the precipitates ranges from 5-30 nm and the thickness of the precipitates varies from 2-10 $\mathrm{nm}$. In addition, our high resolution HAADF-STEM images revealed the presence of G. P. I zones, $\beta$ ' and $\beta_{2}$ and $\beta_{1}$ phases in the matrix (see Fig. 11 (b)). However, significantly higher number density of $\beta$ ' and $\beta_{1}$ precipitates were detected in the peakaged condition where as other phases were found less abundant. The size of the $\beta_{1}$ varies from 10-30 $\mathrm{nm}$ in length and 5-10 $\mathrm{nm}$ in thickness.

Although a uniform distribution of $\beta_{1}$ was detected in the matrix, a sparse presence of large $\beta_{1}$ phase was found in some grains as is evident in Fig. 11 (c). The size of these precipitates were about 300-400 nm long and $10 \mathrm{~nm}$ thick. In addition a large PFZ was observed around these precipitates with about $200 \mathrm{~nm}$ thickness. From the size of the precipitates and the presence of PFZ around them, it can be postulated that these precipitates form at early stages of precipitation. Due to inhomogeneity introduced by PFZ, formation of this region has a negative effect on mechanical properties of the alloys.

\subsection{Over-aged condition}

Fig. 12 (a) and (b) show the HAADF-STEM images of a sample aged at $200^{\circ} \mathrm{C}$ for $64 \mathrm{hr}$, taken near $[10 \overline{1} 0]$ and $[1 \overline{2} 10]$ zone axes, respectively. Examination of the microstructure revealed that 
in this condition, $\beta_{1}$ is the main existing precipitate in the microstructure. In addition to this phase, the presence of the equilibrium $\beta$ phase was detected at gain boundaries as is evident in Fig. 12 (a).

Our TEM analysis of the $\beta$ phase on grain boundaries revealed an FCC lattice structure for this phase with $\mathrm{a}_{\beta}=1.11 \mathrm{~nm}$ as calculated from FFT images in Fig. 13 (b)-(d). In addition, the matrix/precipitate orientation was found to be $(10 \overline{1} 0)_{\mathrm{Mg}} / /(\overline{2} 00)_{\beta}$ and $(1 \overline{2} 12)_{\mathrm{Mg}} / /(020)_{\beta}$ (Fig. 13 (e)). The composition of $\beta$ for the $\mathrm{Mg}-\mathrm{Nd}$ system is reported as $\mathrm{Mg}_{12} \mathrm{Nd}$ [20].

It should be noted that in a few grains, an uneven distribution of needle shape precipitates was found as shown in Fig. 14 (a) and (b). These precipitates lie on basal planes (0001) and are 20-30 $\mathrm{nm}$ long and about 3 atomic layers thick. The orientation of these precipitates with the matrix and their structure are signatures of $\gamma^{\prime}$ reported in Mg-Nd-Zn and Mg-Gd-Zn system [8, 27]. The length of these precipitates is shorter than the reported length in Mg-Gd-Zn system but it is close to the one reported in $\mathrm{Mg}-\mathrm{Nd}-\mathrm{Zn}$ system. The strong strain contrast around each precipitate shows that these precipitates are coherent with the matrix. The structure of this phase is hexagonal with $\mathrm{a}_{\gamma^{\prime}}=0.321 \mathrm{~nm}$ and $\mathrm{c}_{\gamma^{\prime}}=0.781 \mathrm{~nm}[8,27]$.

\section{Discussion}

Table 1 illustrates the summary of the identified precipitation sequence and the microstructure analysis for Mg-3Nd-0.2Zn wt. \% alloy aged at $200^{\circ} \mathrm{C}$. The number densities $\left(\mathrm{N}_{\mathrm{v}}\right)$ of the detected phases in the $2 \mathrm{hr}, 8 \mathrm{hr}$, and $64 \mathrm{hr}$ aged samples are also measured from STEM images and added to table 1. As can be noticed, high number densities of G. P. I, II, and III zones are detected in the $2 \mathrm{hr}$ aged sample indicating that these phases form distinctively from solid 
solution at early stages of precipitation. Additionally, the low number densities of the G. P. zones at peak-aged condition ( $8 \mathrm{hr}$ aged sample) imply the evolution of these phases during aging into next metastable phases in the sequence. On the contrary, low number densities are observed for the $\beta^{\prime}, \beta_{2}$, and $\beta_{1}$ in the $2 \mathrm{hr}$ aged sample; however, the number densities gradually increase up to peak-aged condition indicating the transformation of G. P. zones into metastable $\beta$ phases. At the over-aged condition (i.e. 64hr) the dominant observed precipitates are coarse $\beta_{1}$ within the grains, as was observed in Fig. 12.

According to the obtained results, the sequence of precipitation for this alloy can be then identified as: Super saturated solid solution (SSSS) $\rightarrow$ Clusters of atoms $\rightarrow$ G. P. zones (I, II, III) $\rightarrow \beta^{\prime} \rightarrow \beta_{2} \rightarrow \beta_{1} / \gamma^{\prime} \rightarrow \beta$

Despite there is no report on the presence of clusters of atoms in $\mathrm{Mg}-\mathrm{Nd}-\mathrm{Zn}$ alloys, the results of our STEM and APT analyses revealed formation of clusters of solute atoms in this system. The number density values of clusters obtained from APT analysis and STEM images are presented in table 1. It is noticed that a higher number density of clusters is detected in APT cluster analysis compared to STEM images. The difference can be attributed to two factors: i) the inhomogeneity of the cluster distribution that can create a deviation in the obtained values. The inhomogeneous concentration of clusters in different regions of the sample was also observed in STEM images of the $2 \mathrm{hr}$ aged sample; ii) the small size of the precipitates compared to the thickness of the sample. This factor imposes a limit on detection of small clusters at early stage of precipitation which translates into lower cluster counts.

It was observed that G. P. I zones appear in similar atomic arrangement to D019 structure. The arrangement of atoms in this phase is isomorphic with HCP structure; hence the precipitation can 
progress by replacement of $\mathrm{Nd}$ atoms with Mg atoms. A structural model for the D019 arrangement of $\mathrm{Nd}$ atoms in $\mathrm{Mg}$ matrix is shown in Fig. 15 (a). Although this arrangement has been reported for the structure of $\beta$ " precipitates, no long range ordering (i.e. complete unit cells) with D019 structure was observed in this work. Additionally, the thickness of this phase (one to two atomic layers) and the diffused scattering observed in diffraction patterns and FFT images, taken from the region containing this phase, are common signatures of the G. P. zones. Therefore, in this research, we refer to this phase as G. P. I zones. The absence of the long-range ordered $\beta "$ phase and co-existence of G. P. I zones and $\beta$ ' phase imply that in this system the formation of $\beta$ " is bypassed by transformation of G. P. I zones to $\beta$ ' precipitates. Although this observation seems to deviate from previous reports on this system, it should be noted that the information available on the lattice structure of $\beta$ " in $\mathrm{Mg}-\mathrm{Zn}-\mathrm{RE}$ alloys is only based on the diffraction patterns acquired from the regions containing this phase. In another word, no direct observation of the long range ordered $\beta$ " with complete D019 lattice structure was found in the literature.

The same argument exists in the case of G. P. II zones and G, P. III zones, as the size (in the order of one to two atomic layers) and diffused scattering are observed for these precipitates. In addition, the higher number density observed for such precipitates at early stages of precipitation and the lower number density at the peak-age condition (table 1) clearly shows the evolution of these phases and is in agreement with the identified sequence. Although, the early stage phases can be referred to as "pre-meta stable phase", the "G. P. zones" terminology seems to better identify the characteristics of these phases.

A complete unit cell of D019 with same arrangement of atoms as G. P. I zones results in $\mathrm{Mg}_{3} \mathrm{Nd}$ composition. However, the composition of this phase cannot be determined based on the 
structure due to the short range ordering and lack of defined unit cell.

The structural model for the $\beta$ ' phase is shown in Fig. 15 (b). TEM studies on Mg-Gd [23-25] and $\mathrm{Mg}-\mathrm{Nd}-\mathrm{Zn}[8]$ systems report a base centered orthorhombic $(\mathrm{BCO})$ structure with $\mathrm{a}_{\beta},=0.64$ $\mathrm{nm}, \mathrm{b}_{\beta}=2.23 \mathrm{~nm}, \mathrm{c}_{\beta}=0.52 \mathrm{~nm}$. However, our observations showed a simple orthorhombic arrangement of solute atoms in this phase with an extra solute atom at $\left\{\frac{1}{2}, \frac{1}{6}, \frac{1}{2}\right\}$ and a different value for the lattice parameter $b_{\beta},\left(b_{\beta},=1.11 \mathrm{~nm}\right)$. A comparison between the STEM images obtained from $\beta$ ' phase in $\mathrm{Mg}-\mathrm{Gd}$ alloy and $\mathrm{Mg}-3 \mathrm{Nd}-0.2 \mathrm{Zn}$ alloy, a shift equal to $1 / 2 \mathrm{a}_{\beta}$, was observed for every other zigzag chains in the $\beta$ ' phase in Mg-Gd alloy where no shift was found for $\mathrm{Mg}-3 \mathrm{Nd}-0.2 \mathrm{Zn}$ alloy. This shift results in the same $\mathrm{a}_{\beta}$, and $\mathrm{c}_{\beta}$, and a larger $\mathrm{b}_{\beta}$, lattice parameter $(=2.23 \mathrm{~nm})$ for $\beta^{\prime}$ phase in $\mathrm{Mg}-\mathrm{Gd}$ system [25] compared to what was measured in our study.

From the structure of the $\beta$, the composition of this phase can be obtained as $\mathrm{Mg}_{7} \mathrm{Nd}$ similar to what is reported in literature for this phase [8]. However, the habit plane observed in this research for $\beta^{\prime}$ is the common plane reported for $\beta$ "' $[7,8]$ and has not been reported for $\beta$ ' in $\mathrm{Mg}-\mathrm{Nd}-\mathrm{Zn}$ alloy.

Another interesting point is the presence of hexagon arrangement of atoms in the structure of $\beta$, and G.P. II zones. As seen earlier in Fig. 4 and Fig. 5, the hexagon arrangement of atoms usually appears at the end sides of the precipitate (in longitudinal direction). A possible reason is that the hexagon arrangement of atoms is indeed two opposing 3-atom column components that belong

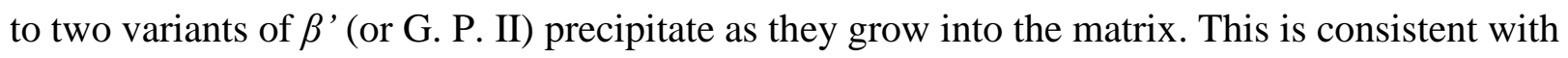
the position of the atoms in the STEM and modeled images in Fig. 4 and Fig. 5.

The structural model for the new detected $\beta_{2}$ phase is shown in Fig. 15 (c). It is evident that the 
$\mathrm{b}_{\beta 2}$ lattice parameter is half of that found for $\beta$ '. In addition, the composition of this phase was calculated based on the structure as $\mathrm{Mg}_{3} \mathrm{Nd}$. This composition is similar to what was reported previously for $\beta$ " and $\beta_{1}$. The transition of the composition from $\mathrm{Mg}_{7} \mathrm{Nd}$ to $\mathrm{Mg}_{3} \mathrm{Nd}$ along with the structural change in $\beta_{2}$ suggest that this phase is a transition phase in transformation of $\beta$, phase to $\beta_{1}$ phase.

In terms of $\beta_{1}$ precipitates, we constructed the position of solute atoms as well as $\mathrm{Mg}$ atoms inside the precipitate based on high resolution HAADF-STEM images in Fig. 8 and the corresponding modeled images. The structural model for this phase is presented in Fig. 15 (d). A unit cell of BCT $\beta_{1}$ is indicated in the model. It was found out that the lattice structure of $\beta_{1}$ is in fact a body centered tetragonal (BCT) lattice with extra atoms at $\left\{0, \frac{1}{2}, \frac{1}{4}\right\} .\left\{\frac{1}{2}, 1, \frac{1}{4}\right\},\left\{0, \frac{1}{2}, \frac{3}{4}\right\}$, $\left\{\frac{1}{2}, 1, \frac{1}{4}\right\},\left\{0,1, \frac{1}{2},\left\{1,0, \frac{1}{2}\right\},\left\{0,0, \frac{1}{2}\right\},\left\{1,1, \frac{1}{2}\right\},\left\{\frac{1}{2}, \frac{1}{2}, 0\right\}\right.$ and $\left\{\frac{1}{2}, \frac{1}{2}, 1\right\}$ positions. From the modeled images, the lattice parameters were calculated as $\mathrm{a}_{\beta 1}=0.52 \mathrm{~nm}, \mathrm{~b}_{\beta 1}=0.52 \mathrm{~nm}, \mathrm{c}_{\beta 1}=0.74 \mathrm{~nm}$. The previous structure (FCC) for this phase [20] is also presented in yellow lines. One can see that although the arrangement of atoms in the phase correlates with the FCC structure, it does not represent the smallest repeating unit in this structure. The orientation relationship of BCT $\beta_{1}$ with the matrix can be written as $(10 \overline{1} 0)_{\mathrm{Mg}} / /(100)_{\beta 1}$ and $(1 \overline{2} 10)_{\mathrm{Mg}} / /(001)_{\beta 1}$. The composition of this phase based on the new structure is calculated as $\mathrm{Mg}_{3} \mathrm{Nd}$ similar to what previously reported for this phase.

The distribution of solute atoms in the precipitates which was acquired from APT ion maps (see Fig. 10) revealed that the precipitates are not only enriched in Nd (indicated by green color), but contain higher content of $\mathrm{Zn}$ with respect to the matrix. Two main compositions were found for the precipitates as $\mathrm{Mg}-11 \mathrm{Nd}-4 \mathrm{Zn}$ and $\mathrm{Mg}-21 \mathrm{Nd}-5 \mathrm{Zn}$ (at. \%), which are in close proximity with 
the theoretical compositions for $\beta$ ' and $\beta_{1}$ phases, respectively. Since the amount of Nd atoms found by APT is less than what we expected from the structure of the precipitates, it is more likely that $\mathrm{Zn}$ atoms replace a portion of $\mathrm{Nd}$ atoms in the structure of the metastable phases. Since the atomic radius of $\mathrm{Zn}$ is smaller than $\mathrm{Mg}$ and $\mathrm{Nd}$, the substitution of $\mathrm{Zn}$ atoms with $\mathrm{Nd}$ atoms can reduce the strain energy that is associated with the presence of larger Nd atoms in the structure.

\section{Conclusion}

1. Careful STEM and TEM analyses of the microstructure of the samples aged at $200^{\circ} \mathrm{C}$ revealed the presence of some new phases in the microstructure in addition to the old description Super saturated solid solution $($ SSSS $) \rightarrow G$. P. zones $\rightarrow \beta^{\prime \prime} \rightarrow \beta$ ' $\rightarrow \beta$, reported for binary $\mathrm{Mg}-\mathrm{Nd}$ alloy. The precipitation sequence for this alloy was identified as: Super saturated solid solution (SSSS) $\rightarrow$ Clusters of atoms $\rightarrow$ G. P. zones $(I, I I$, III $) \rightarrow \beta$ ' $\rightarrow \beta_{2} \rightarrow$ $\beta_{1} / \gamma^{\prime} \rightarrow \beta$

2. The presence of clusters of solute atoms was confirmed by STEM and APT techniques. The formations of atom clusters, G. P. zones, and $\beta_{2}$ phase have not been reported for the binary Mg-Nd and ternary Mg-Nd-Zn system. Similarity of the structure of G. P. zones I and II with $\beta$ ' and G. P. zones III with $\beta_{2}$ shows that G. P. zones serve as nuclei for $\beta$ ' and $\beta_{2}$ phases.

3. Our measurements showed that the lattice parameter $\mathrm{b}$ for the orthorhombic $\beta$ ' phase is different from the one reported for Mg-RE alloys. Our microstructure observations showed that this is due to a different arrangement of atoms in $\beta$ ' phase formed in $\mathrm{Mg}-\mathrm{Nd}-\mathrm{Zn}$ alloy.

4. The intermediate $\beta_{2}$ phase detected in this study is a new phase with orthorhombic structure, lattice parameters of $\mathrm{a}_{\beta 2}=0.64 \mathrm{~nm}, \mathrm{~b}_{\beta 2}=0.56 \mathrm{~nm}, \mathrm{c}_{\beta 2}=0.52 \mathrm{~nm}$ and composition of $\mathrm{Mg}_{3} \mathrm{Nd}$. 
Our analysis showed that this phase is a transition phase in the transformation of $\beta$ ' to $\beta_{1}$.

5. The structural model based on high resolution STEM images showed that the structure of $\beta_{1}$ is indeed BCT with rather than reported FCC structure for this phase. The lattice parameters for this phase are $\mathrm{a}_{\beta 1}=0.52 \mathrm{~nm}, \mathrm{~b}_{\beta 1}=0.52 \mathrm{~nm}, \mathrm{c}_{\beta 1}=0.74 \mathrm{~nm}$.

\section{Acknowledgement}

The authors would like to acknowledge the financial support provided by National Science

Foundation, DMR GOALI Program (Grant No. 1005762), and use of instrumentation supported by the UW MRSEC (DMR-1121288) and the UW NSEC (DMR-0832760).

\section{References}

[1] Z. Xingwei, D. Jie, L. Wencai, D. Wenjiang, Res. Dev. 2011; 8: 41.

[2] N. Stanford, M. Barnett, Scripta Mater. 2008; 58: 179.

[3] R. Gehrmann, M. M. Frommert, G. Gottstein, J. Mater. Sci. Eng. A 2005; 395: 338.

[4] K. Hantzsche, J. Bohlen, J. Wendt, K. Kainer, S. Yi, D. Letzig, Scripta Mater. 2010; 63: 725.

[5] R. K. Mishra, A. K. Gupta, P. R. Rao, A. K. Sachdev, A. Kumar, A. Luo, Scripta Mater. 2008; 59: 562.

[6] D. Wu, R. S. Chen, E. H. Han, J. alloys Comp. 2011; 509: 2856.

[7] T. J. Pike, B. Noble, J. the Less-Common Met. 1973; 30: 63.

[8] L. Ma, R. K. Mishra, M. P. Balogh, L. Peng, A. A. Luo, A. K. Sachdev, W. Ding, J. Mater. Sci. Eng. A 2012; 543: 12.

[9] P. A. Nuttall, T. J. Pike, B. Noble, Metallography 1980; 13: 3.

[10] X. Zheng, A. A. Luo, J. Dong, A. K. Sachdev, W. Ding, Mat. Sci. Eng. A 2012; 532: 616. 
[11] J. Dai, J. Huang, M. Li, Z. Li, J. Dong, Y. Wu, Mat. Sci. Eng. A 2011; 529: 401.

[12] W.J. Ding, P.H. Fu, L.M. Peng, H.Y. Jiang, X. Q. Zeng, Mat. Sci. Forum 2007; 546-549: 433.

[13] X. Zheng, J. Dong, Y. Xiang, J. Chang, F. Wang, L. Jin, Y. Wang, W. Ding, Mater. Des. $2010 ; 31: 1417$.

[14] W. Wen-Xiang, J. Li, D. Jie, D. Wen-Jiang, Trans. Nonferr. Met. Soc. China 2012; 22: 1169.

[15] D. Wenjiang, L. Daquan, W. Qudong, L. Qiang, Mater. Sci. Eng. A 2008; 483-484: 228.

[16] Q. Li, Q. Wang, Y. Wang, X. Zeng, W. Ding, J. Alloys Comp. 2007; 427: 115.

[17] X. Zhou, H. Zhou, Z. Zhang, R. Liu, L. Liu, Adv. Mat. Res. 2012; 415-417: 1157.

[18] Y. Lin, G. Xiao-dan, L. Li, Z. Peng, C. Li-Jia, L. Zheng, Trans. Nonferr. Met. Soc. China 2010; 20: s498.

[19] R. Wilson, C. J. Bettles, B. C. Muddle, J. F. Nie, Mater. Sci. Forum 2003; 419-422: 267.

[20] J. F. Nie, B. C. Muddle, Acta Mater. 2000; 48: 1691.

[21] K. Saito, K. Hiraga, Mat. Trans. 2011; 52: 1860.

[22] J. F. Nie, Scripta Materialia 2003; 48: 1009.

[23] T. Honma, T. Ohkubo, K. Hono, S. Kamado, Mat. Sci. Eng. A 2005; 395: 301.

[24] S. M. He, X. Q. Zeng, L. M. Peng, X. Gao, J. F. Nie, W. J. Ding, J. Alloy. Comp. 2006; 421: 309 .

[25] M. Nishijima, K. Hiraga, Mater. Trans. 2007; 48: 10.

[26] P. A. Carvalho, M. Sijbolts, B. J. Kooi, J. Th. M. De Hosson, Acta Mater. 2000; 48: 4203.

[27] J. F. Nie, K. Oh-ishi, X. Gao, K. Hono, Acta Mat. 2008; 56: 6061.

[28] T. Malis, S. C. Cheng, R. F. Egerton, J. Elec. Micro. Tech. 1988; 8:193. 
[29] T. Honma, T. Ohkubo, S. Kamado, K. Hono, Acta Mater. 2007; 55: 4137.

[30] X. Gao, S. M. He, X. Q. Zeng, L. M. Peng, W. J. Ding, J. F. Nie, Mat. Sci. Eng. A 2006; 431: 322 .

[31] C. Antion, P. Donnadieu, F. Perrard, A. Deschamps, C. Tassin, A. Pisch, Acta Mater. 2003; 51: 5335 . 


\section{Figure captions}

Fig. 1. Hardness as a function of annealing time for the $\mathrm{Mg}-3 \mathrm{Nd}-0.2 \mathrm{Zn}$ (wt. \%) samples aged at $200^{\circ} \mathrm{C}$.

Fig. 2. HAADF-STEM micrograph taken from sample aged at $200^{\circ} \mathrm{C}$ for $2 \mathrm{hr}$. The beam is parallel to [0001] direction.

Fig. 3. High resolution HAADF-STEM images and corresponding modeled atomic arrangements for the first type precipitate in the alloy aged at $200^{\circ} \mathrm{C}$ for $2 \mathrm{hr}$. The beam is parallel to: a) and b) [0001] direction; c) and d) [1 $\overline{2} 10]$ direction; e) and f) [10 $\overline{1} 0]$ direction. In the modeled structure, $\mathrm{Mg}$ and $\mathrm{Nd}$ atoms at different layers are denoted with smaller and bigger circles and different colors

Fig. 4. High resolution HAADF-STEM images and corresponding modeled atomic arrangements for the second type precipitate in the alloy aged at $200^{\circ} \mathrm{C}$ for $2 \mathrm{hr}$. The beam is parallel to: a) and b) [0001] direction; c) and d) [1 $\overline{2} 10]$ direction; e) and f) [10 $\overline{1} 0]$ direction. In the modeled structure, $\mathrm{Mg}$ and $\mathrm{Nd}$ atoms at different layers are denoted with smaller and bigger circles and different colors.

Fig. 5. a) High resolution HAADF-STEM image and; b) the corresponding model showing second type G. P. zones (G. P. II) detected in the sample aged at $200^{\circ} \mathrm{C}$ for $2 \mathrm{hr}$. The region containing G. P. II type is magnified in the left image.

Fig. 6. a) High resolution HAADF-STEM image; and b) the corresponding model showing third type precipitate in the sample aged at $200^{\circ} \mathrm{C}$ for $2 \mathrm{hr}$. The region containing $\beta_{2}$ and a unit cell of this phase are magnified and shown in the left image.

Fig. 7. (a) and (b) High resolution HAADF-STEM images and; (c) the modeled image showing the presence of G. P. III zones in the microstructure. The beam is parallel to [0001] direction. 
Fig. 8. High resolution HAADF-STEM images and corresponding modeled atomic arrangements for the fourth type precipitate. The sample is aged at $200^{\circ} \mathrm{C}$ or $2 \mathrm{hr}$. The beam is parallel to: a) and b) [0001] direction; c) and d) [12̄10] direction; e) and f) [10 $\overline{1} 0]$ direction. In the modeled structure, $\mathrm{Mg}$ and $\mathrm{Nd}$ atoms at different layers are denoted with smaller and bigger circles and different colors.

Fig. 9. a) High resolution HAADF-STEM images showing the presence of clusters of atoms in the $2 \mathrm{hr}$ aged sample. The beam is parallel to a) [0001]; b) [10 $\overline{1} 0]$; and c) [1 $\overline{2} 10]$ directions. Fig. 10. APT reconstruction and elemental maps in the sample aged at $200^{\circ} \mathrm{C}$ for $2 \mathrm{hr}$. The maps show the distribution of $\mathrm{Nd}$ (green), $\mathrm{Zn}$ (red), and $\mathrm{Zr}$ (purple) in the matrix and precipitates. Fig. 11. a) HAADF-STEM image of the $8 \mathrm{hr}$ aged sample; b) high resolution image showing the presence of different phases in the microstructure at this aging condition; c) the presence of large $\beta_{1}$ precipitates and PFZ region around them. The beam is parallel to [0001] direction.

Fig. 12. HAADF-STEM images of the sample aged at $200^{\circ} \mathrm{C}$ for $64 \mathrm{hr}$ (over-aged condition). The beam is parallel to: a) [10 $\overline{1} 0]$ and b) [1210]. The presence of $\beta 1$ and $\beta$ is evident at this aging condition.

Fig. 13. TEM micrographs of the sample aged for $64 \mathrm{hr}$ at $200^{\circ} \mathrm{C}$. a) BF image showing the $\beta$ phase on grain boundaries; b) HREM image of the $\beta$ on grain boundary; c) FFT taken from region A; d) FFT taken from region B; and e) FFT of the (b) image.

Fig. 14. (a) Bright field TEM and; (b) high resolution TEM images of the $\gamma$ ' in the matrix for sample aged at $200^{\circ} \mathrm{C}$ for $64 \mathrm{hr}$. Images are taken with electron beam parallel to [12 10$]$. Fig. 15. Atomic models deduced from high resolution HAADF-STEM images for the: a) G. P. I zones; b) $\beta$ '; c) $\beta_{2}$ and d) $\beta_{1}$ phase with BCT structure. The FCC lattice previously reported for $\beta_{1}$ phase is shown in yellow lines for comparison. 


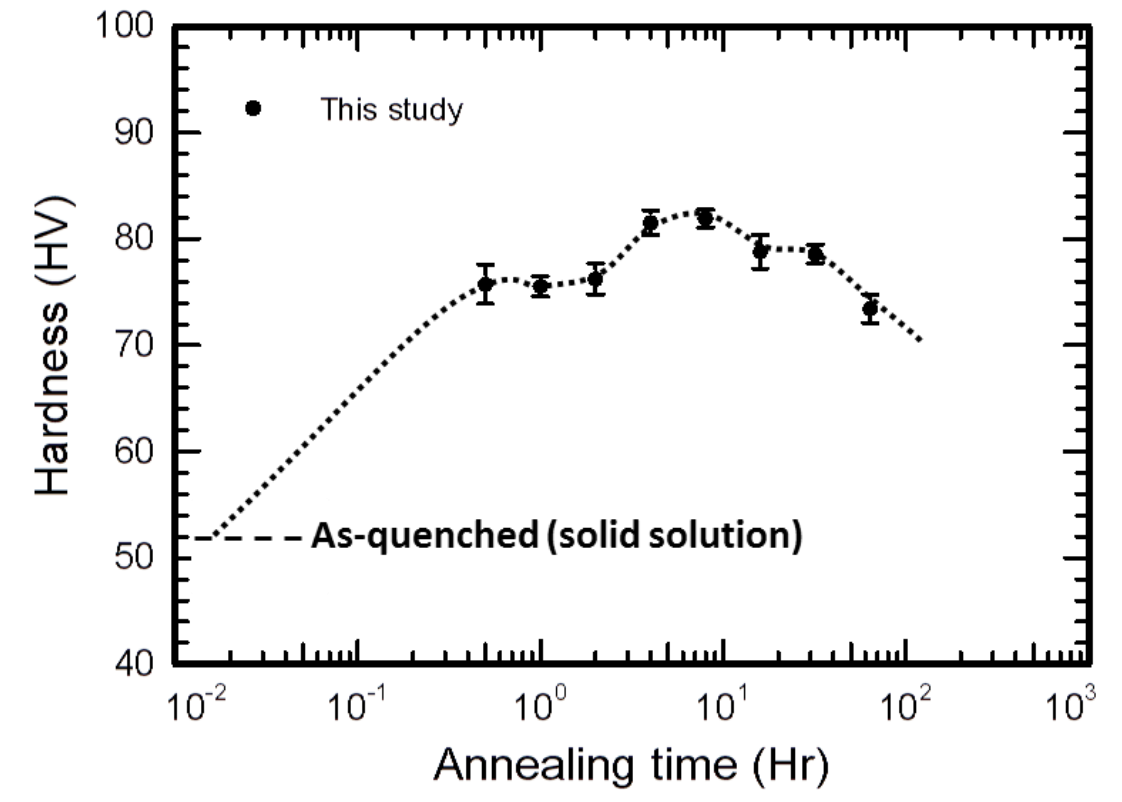

Fig. 1

Figure 


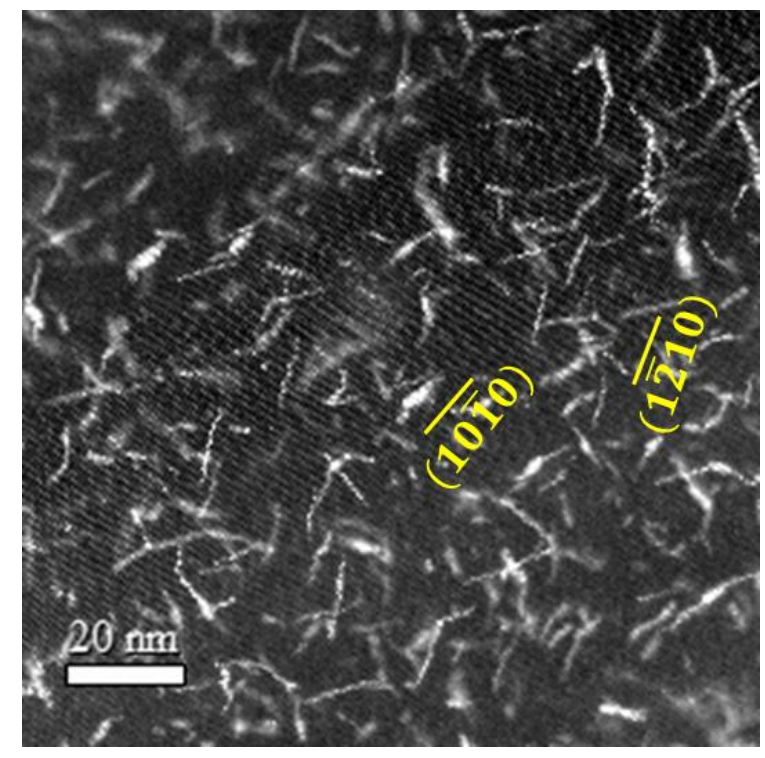

Fig. 2 

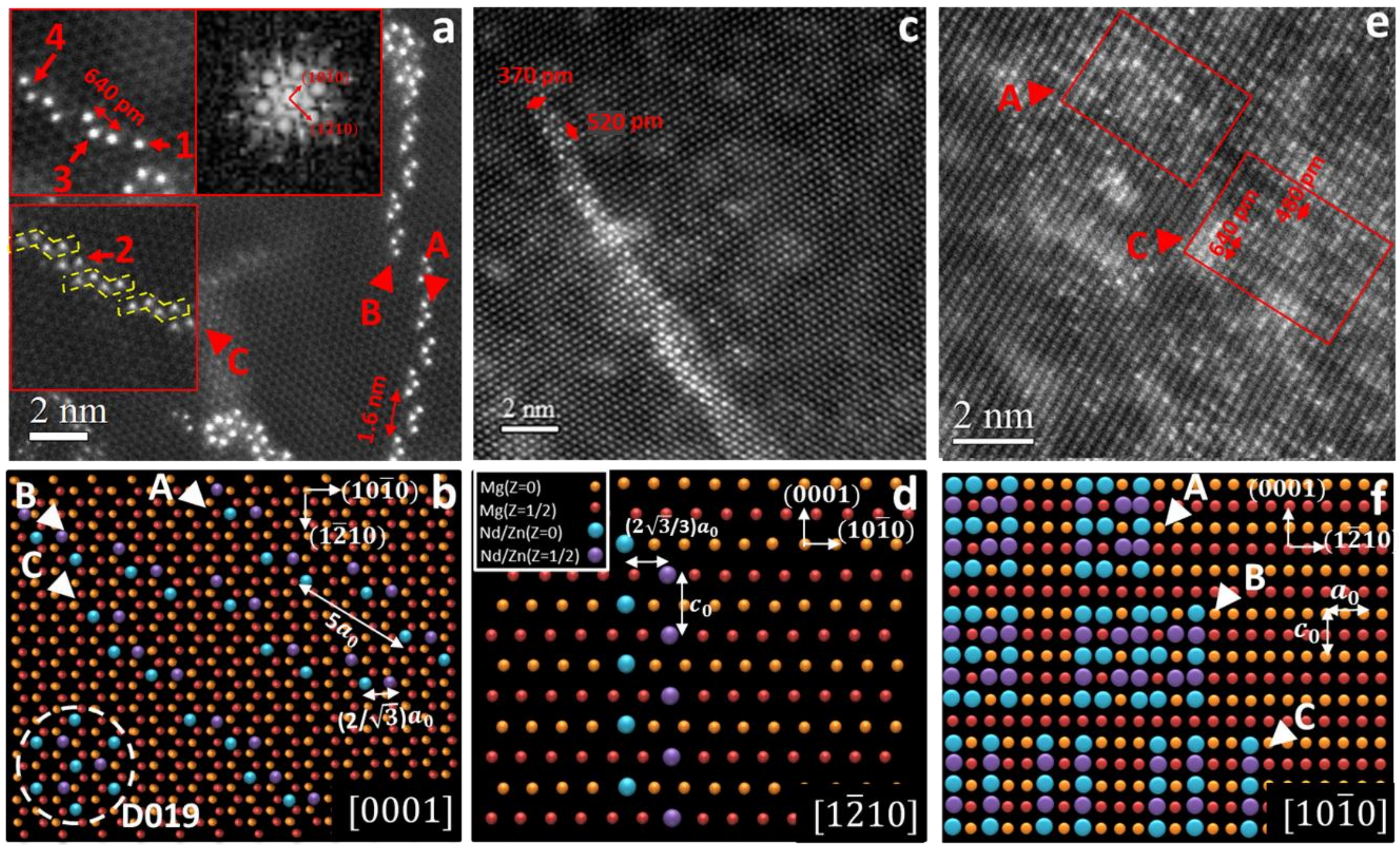

Fig. 3 

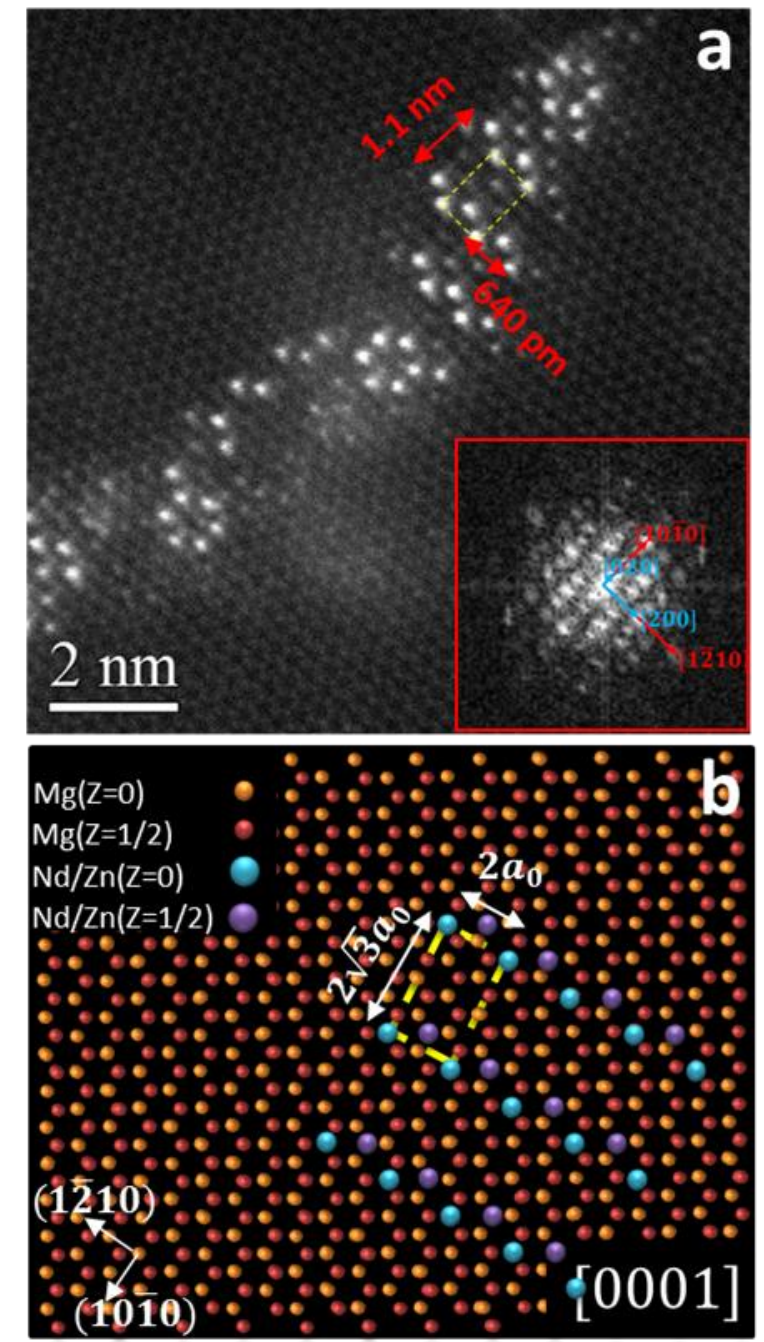
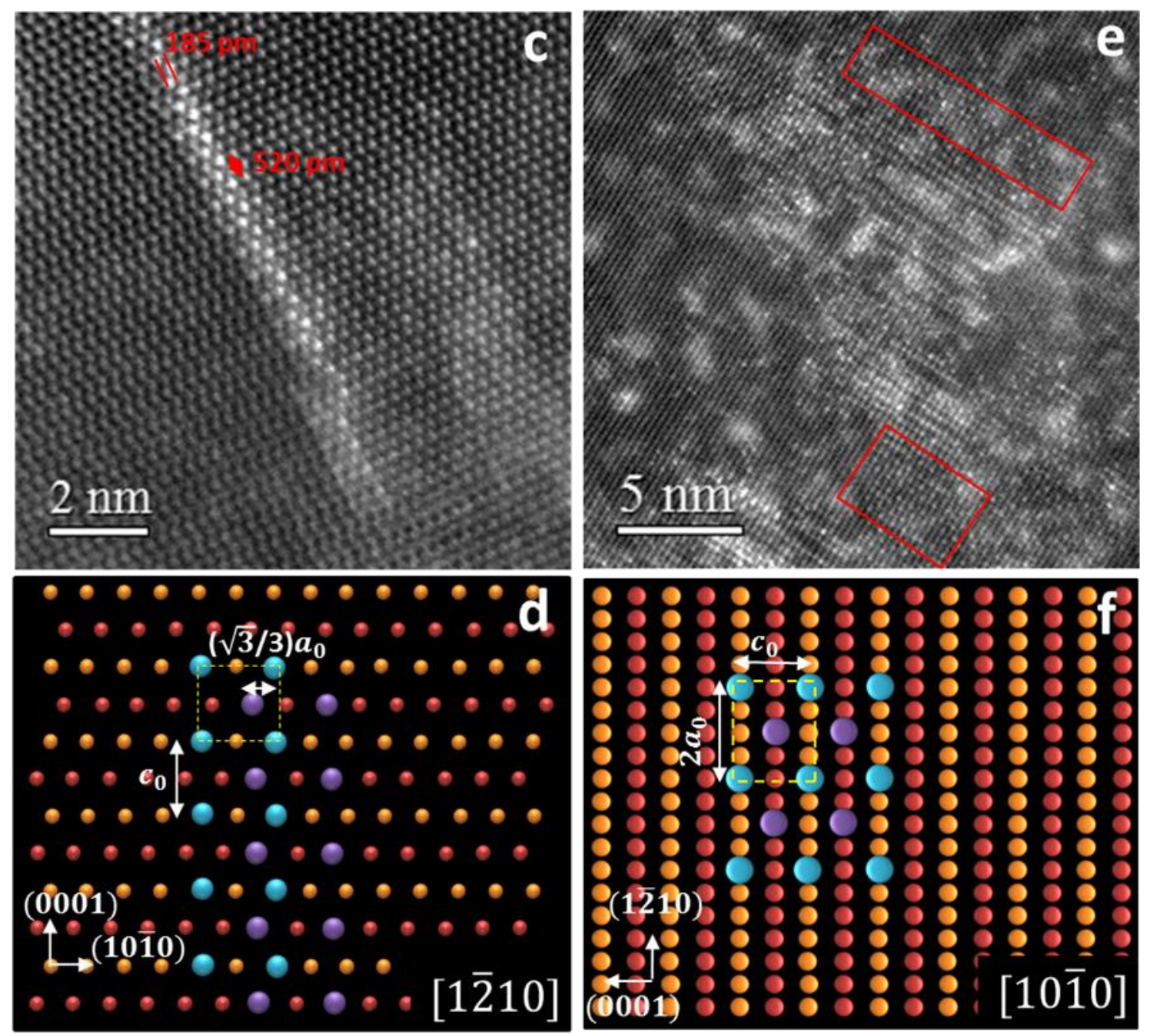

Fig. 4 

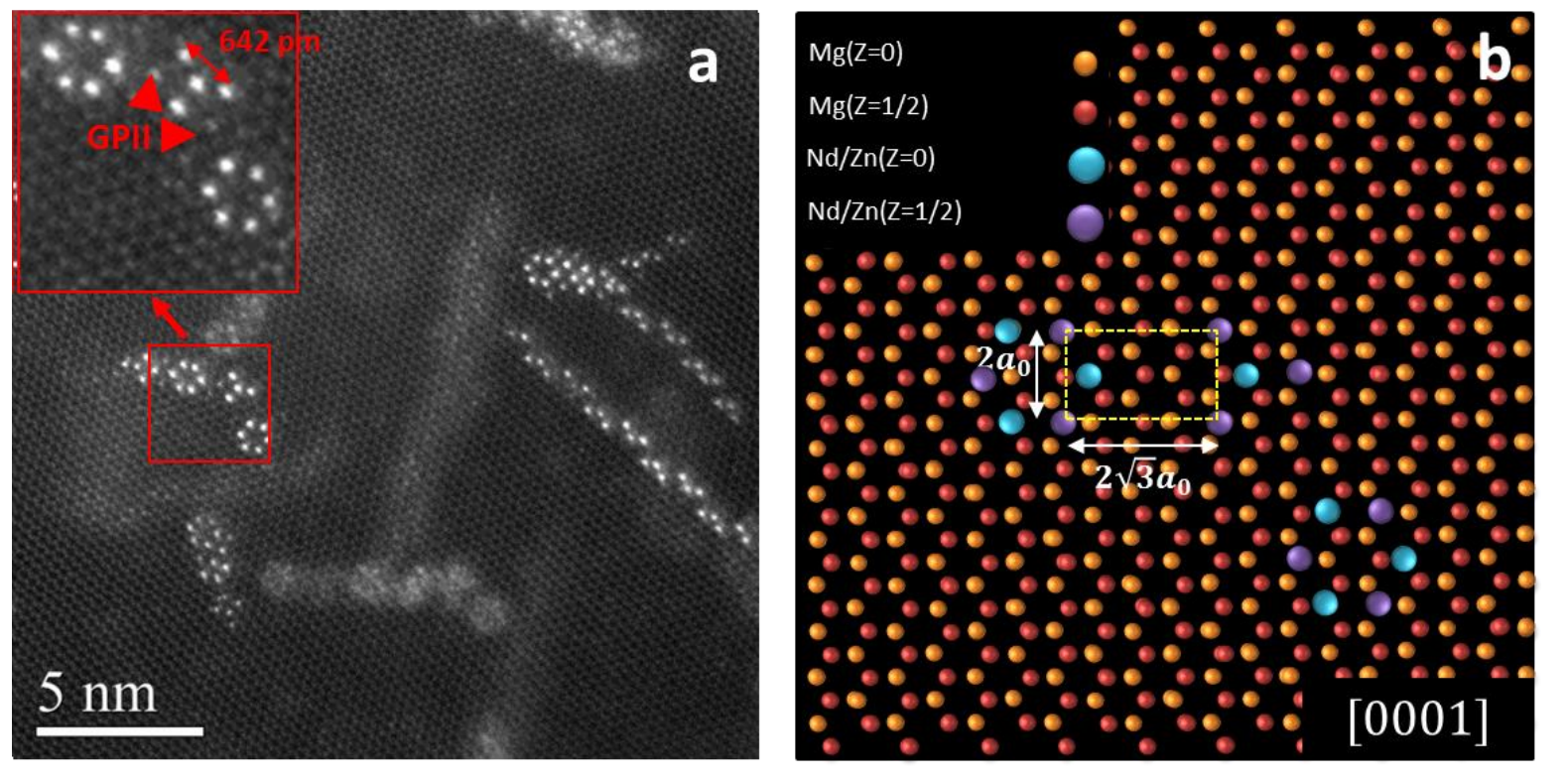

Fig. 5

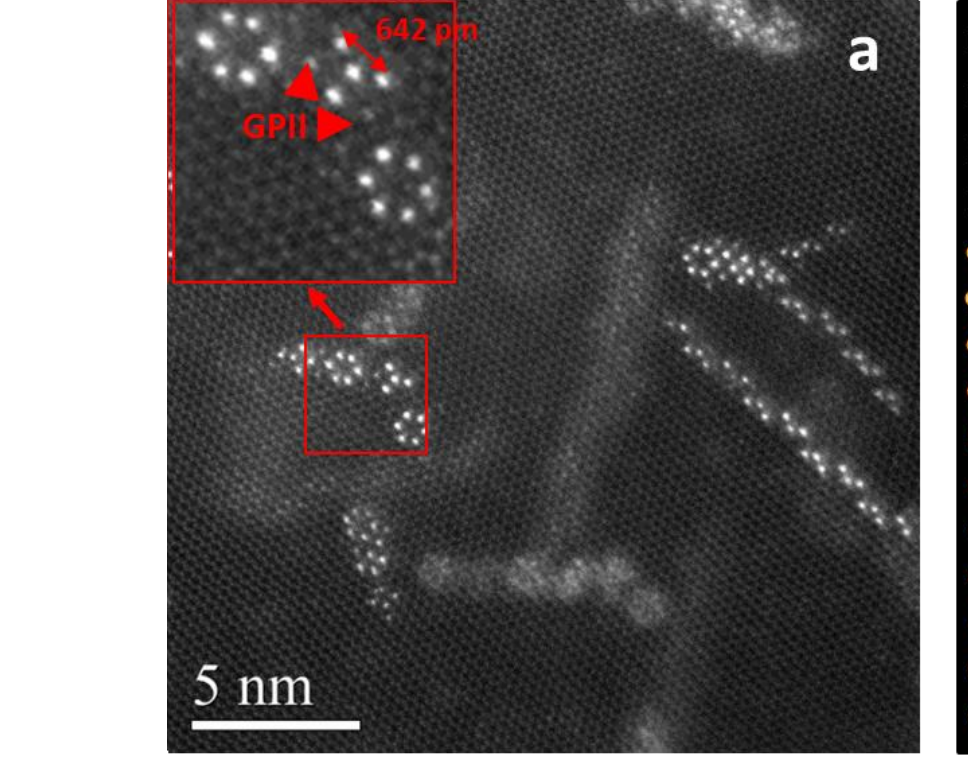

5

,

.

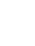

5
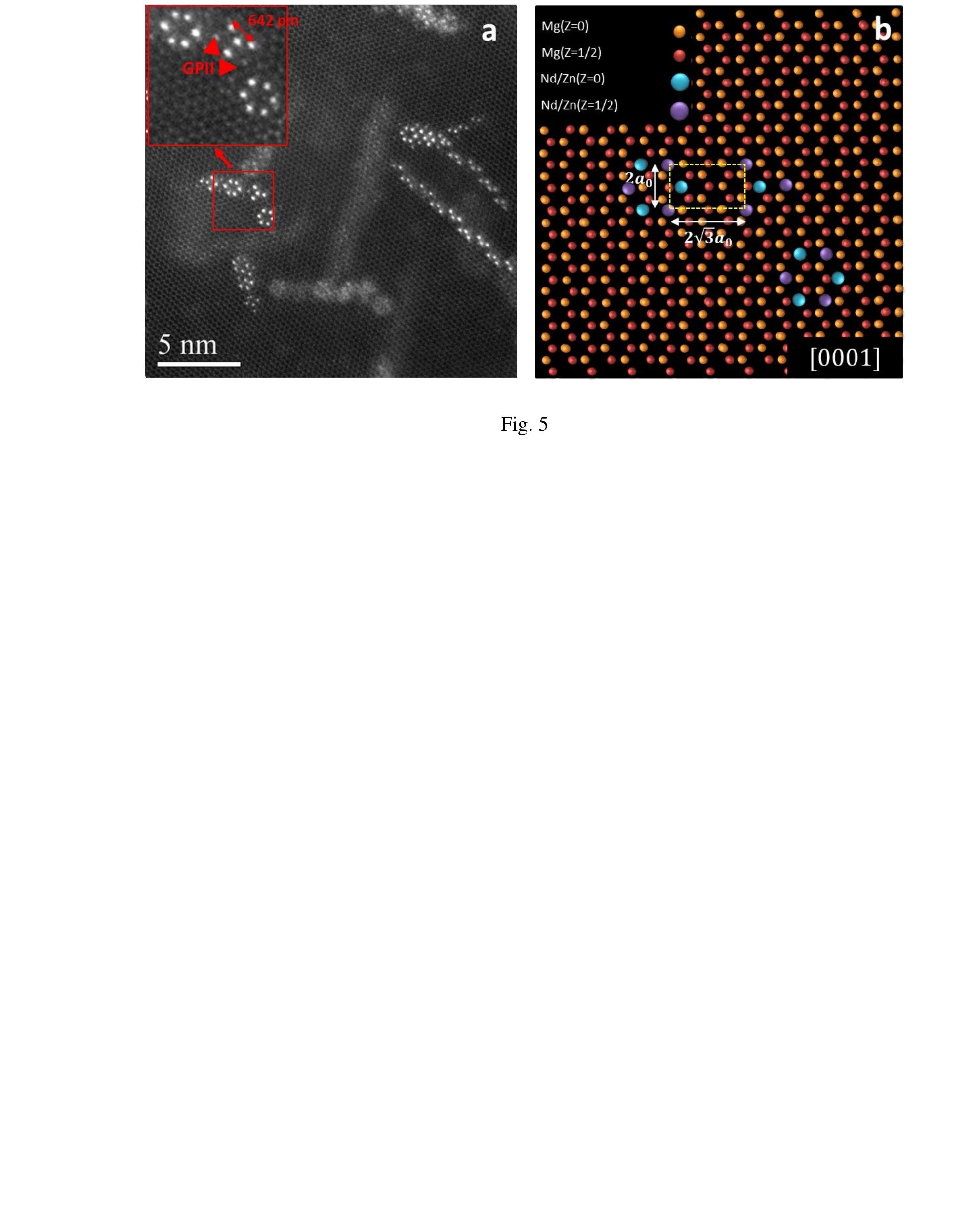

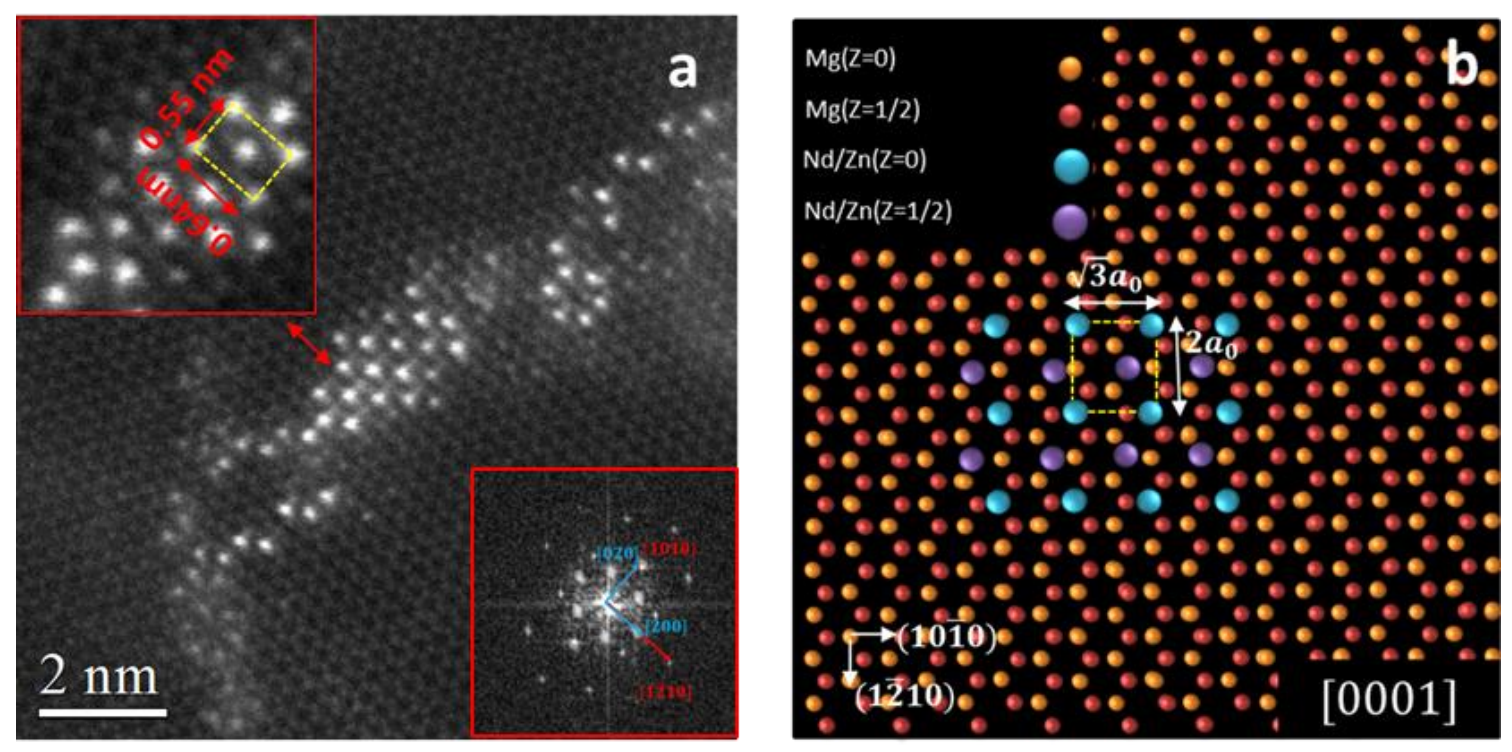

Fig. 6

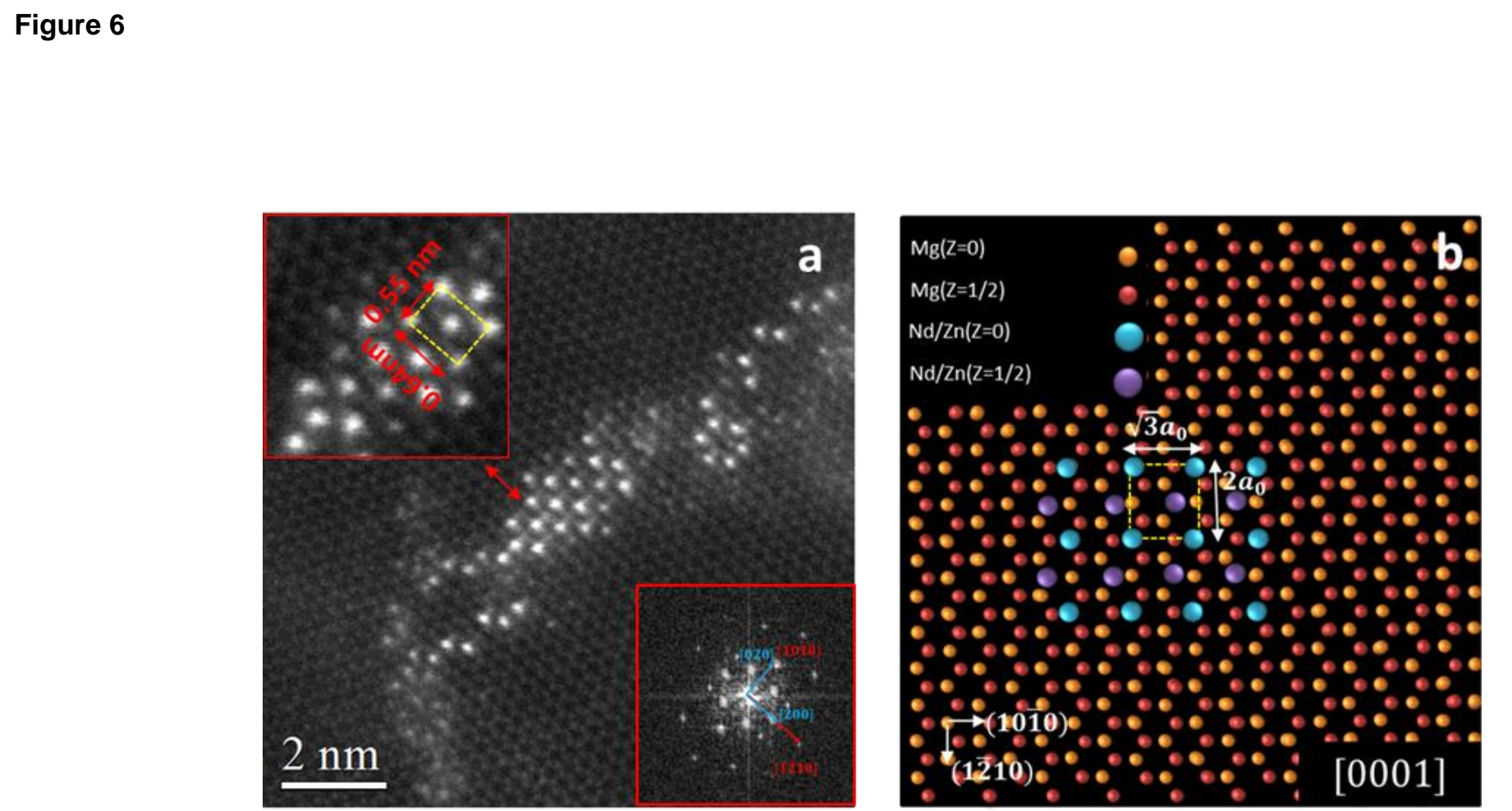
6
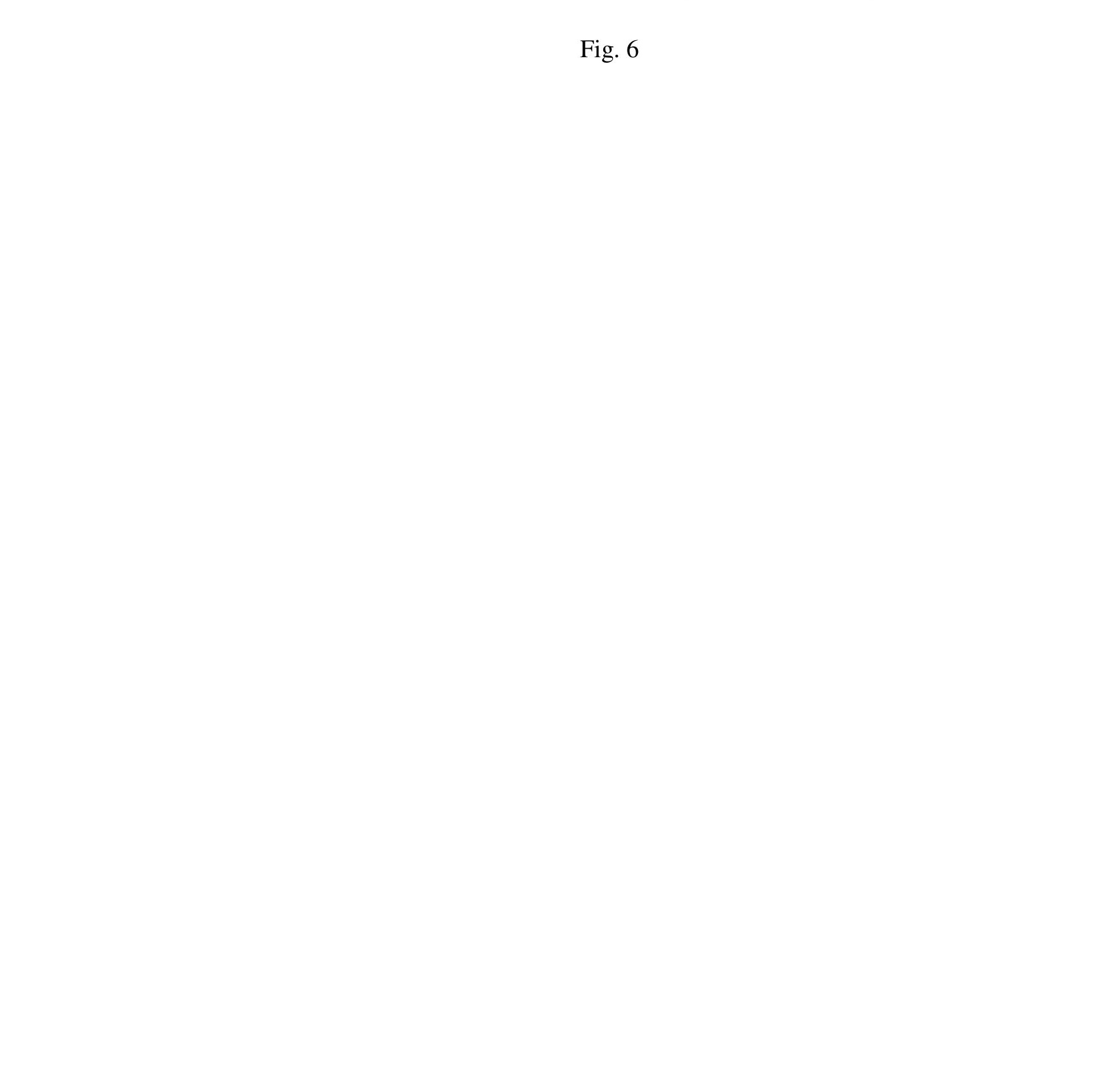

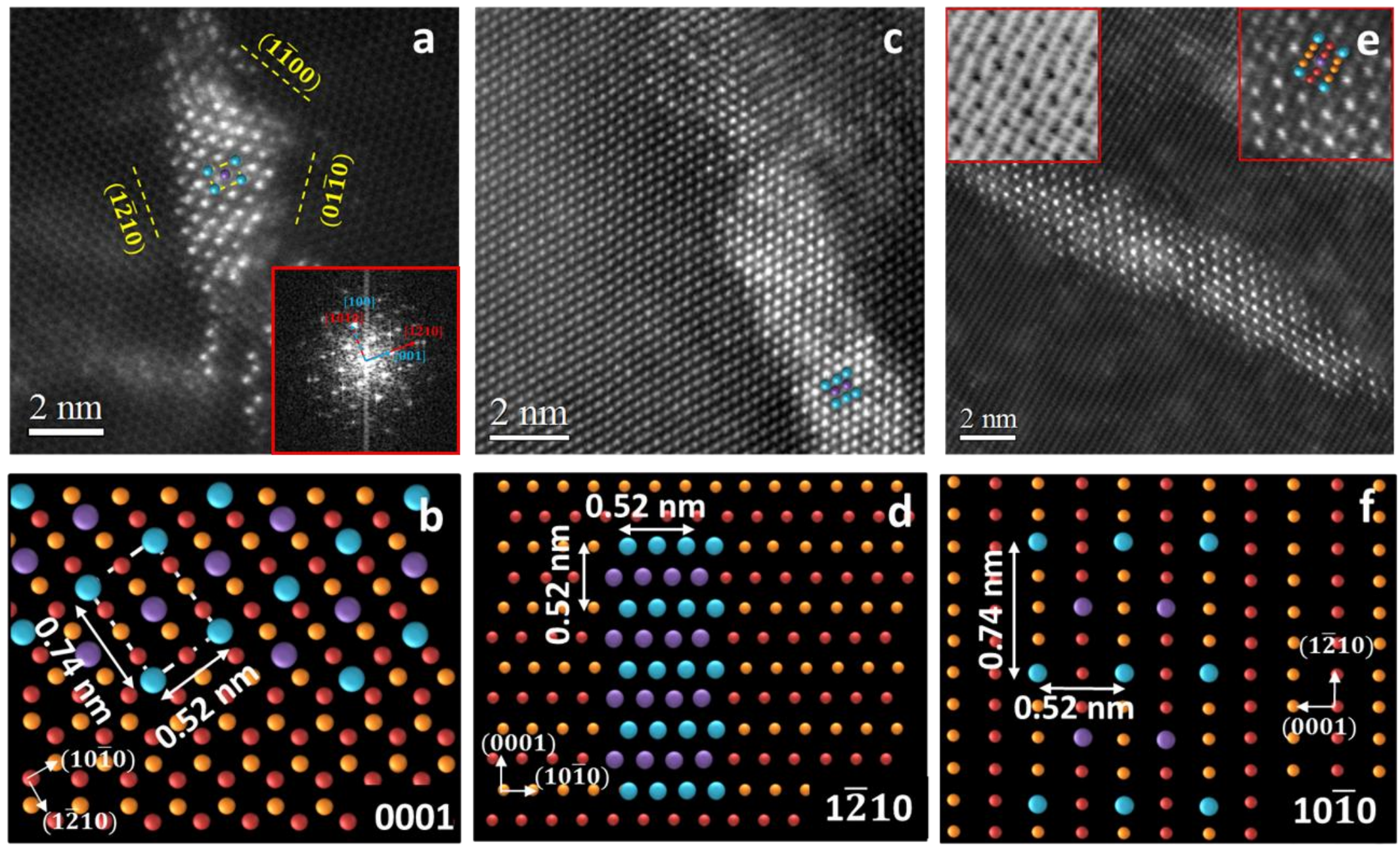

Fig. 8 

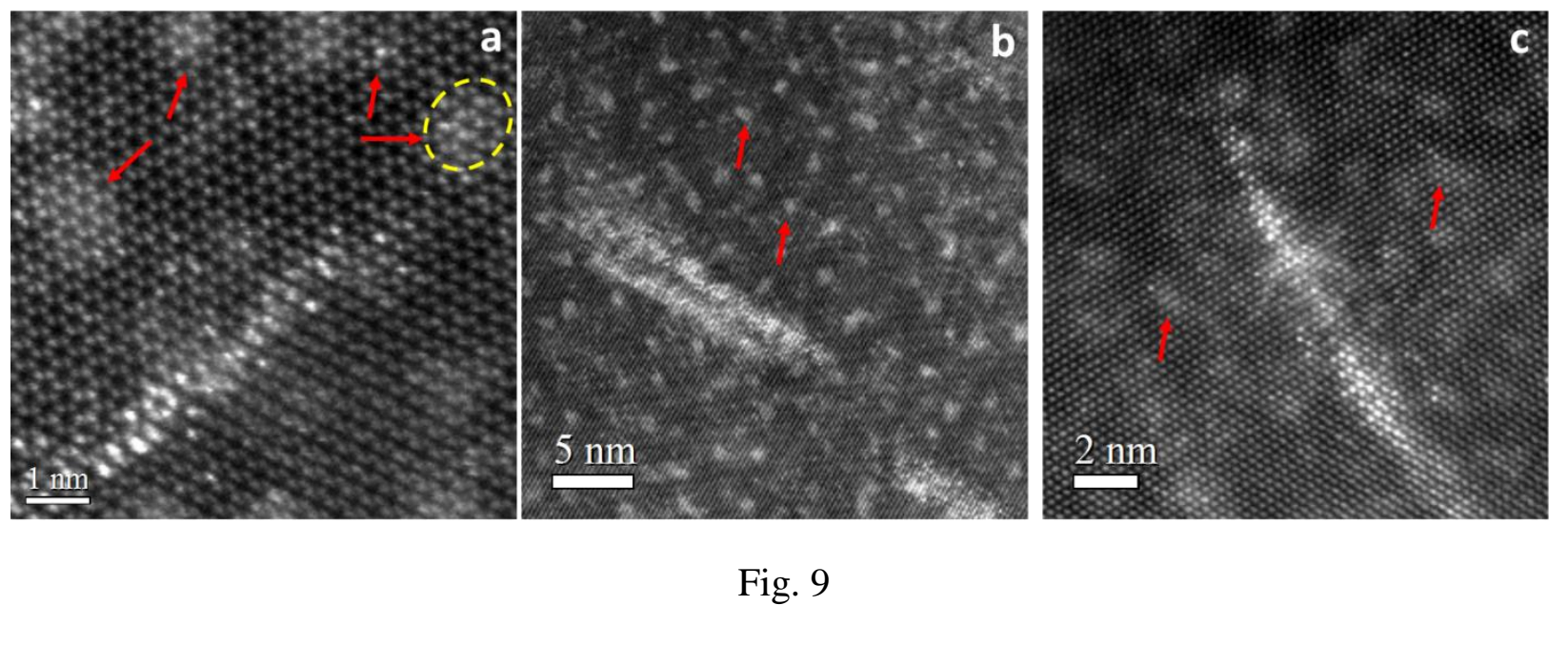

Fig. 9

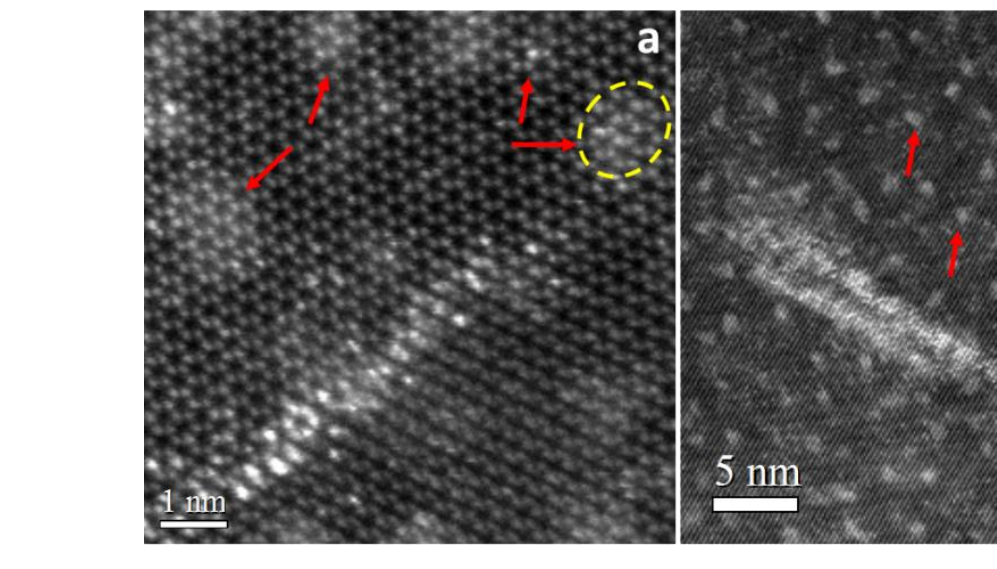

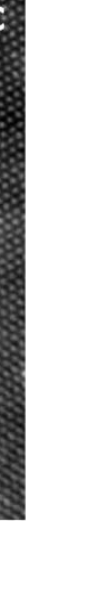

-

(

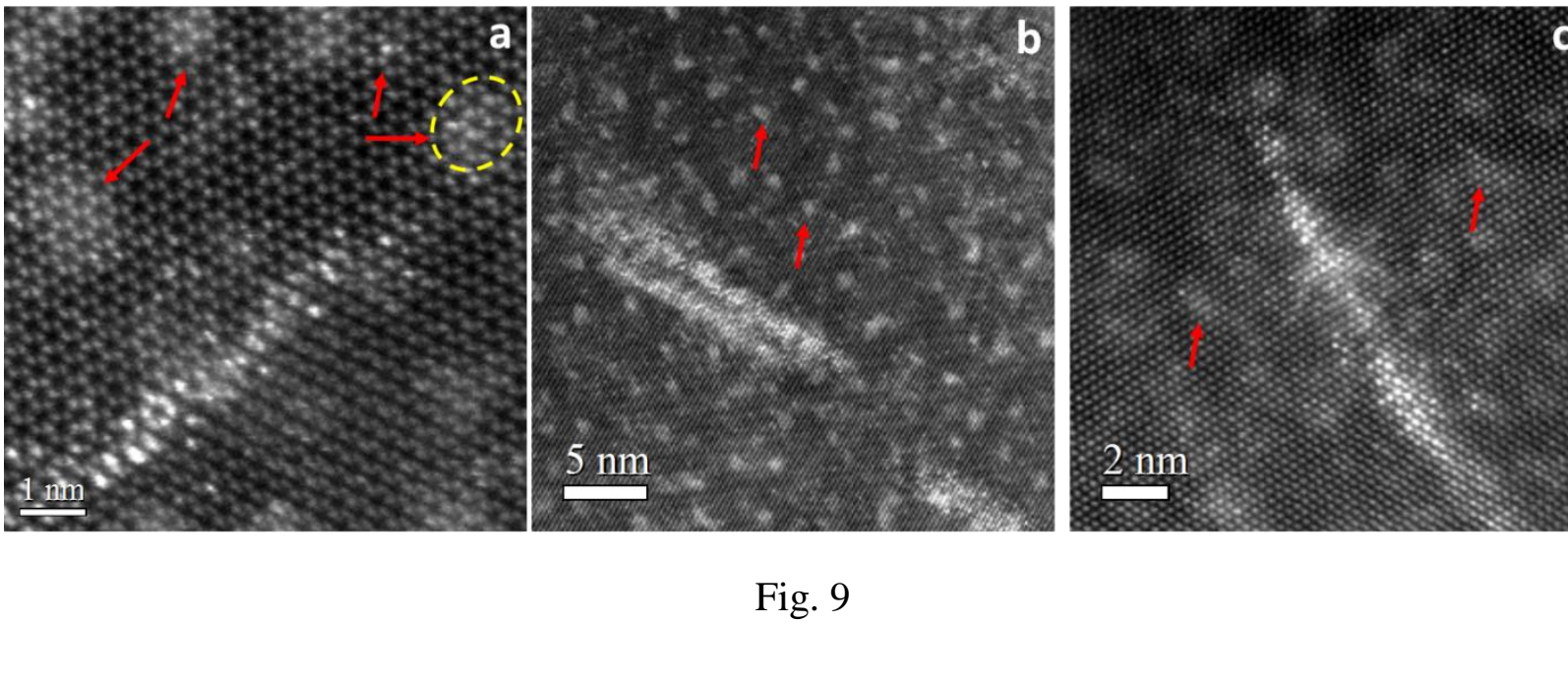

\section{.

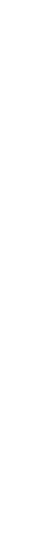

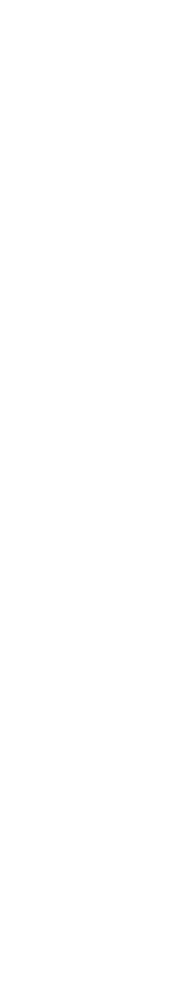
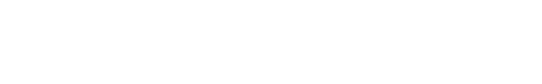

Figure 9
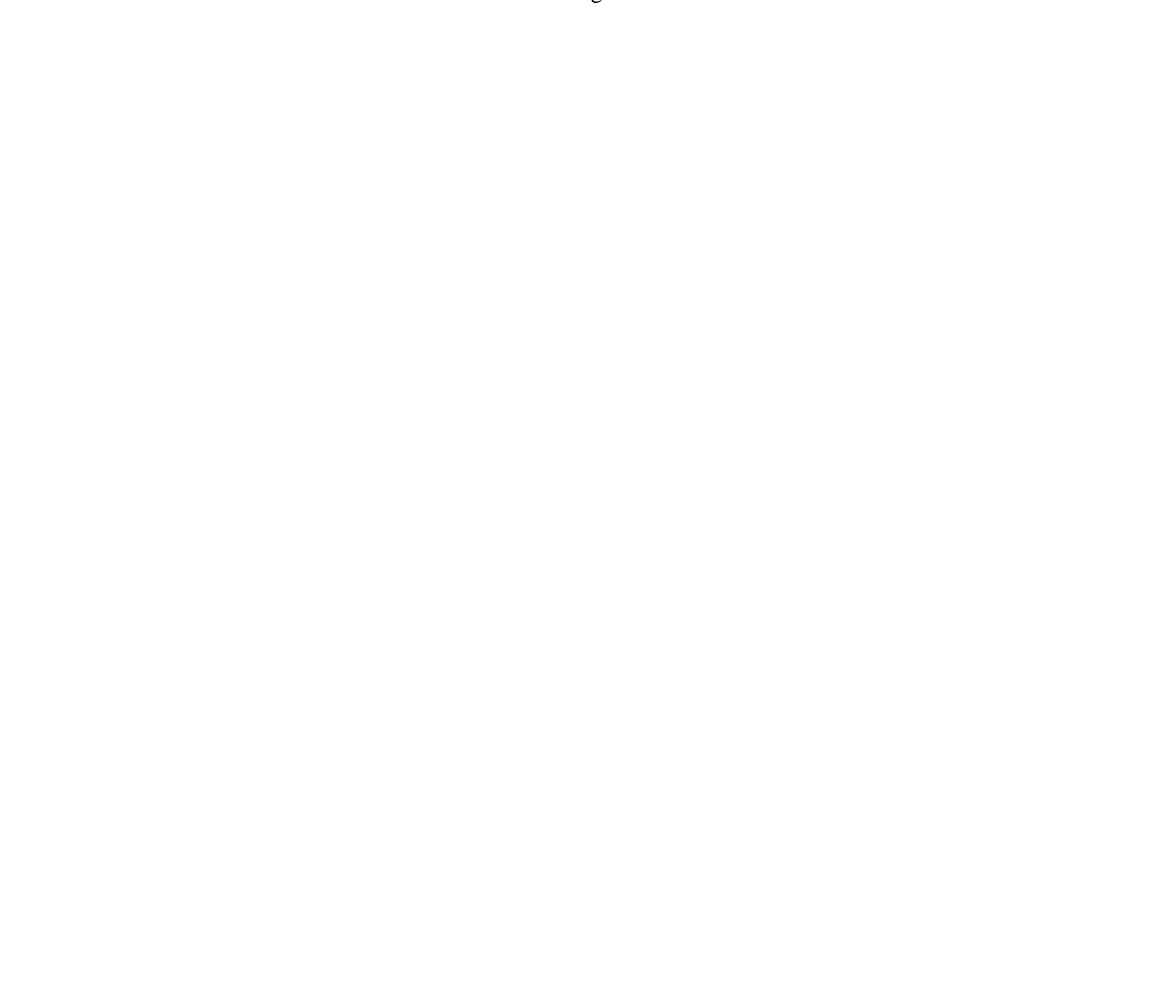

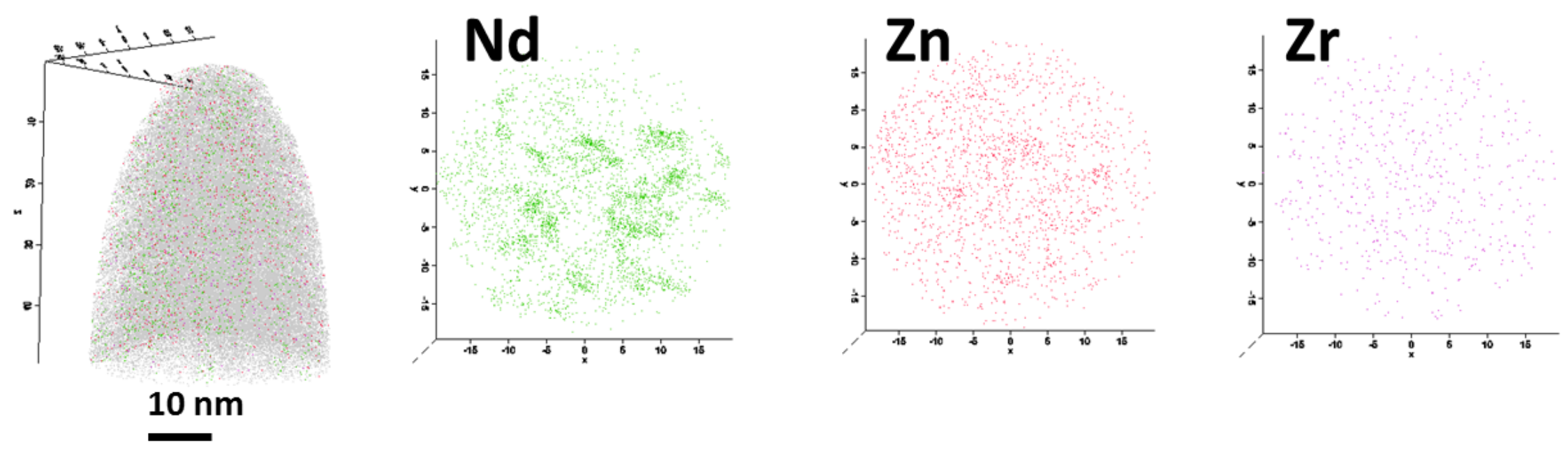

Fig. 10 

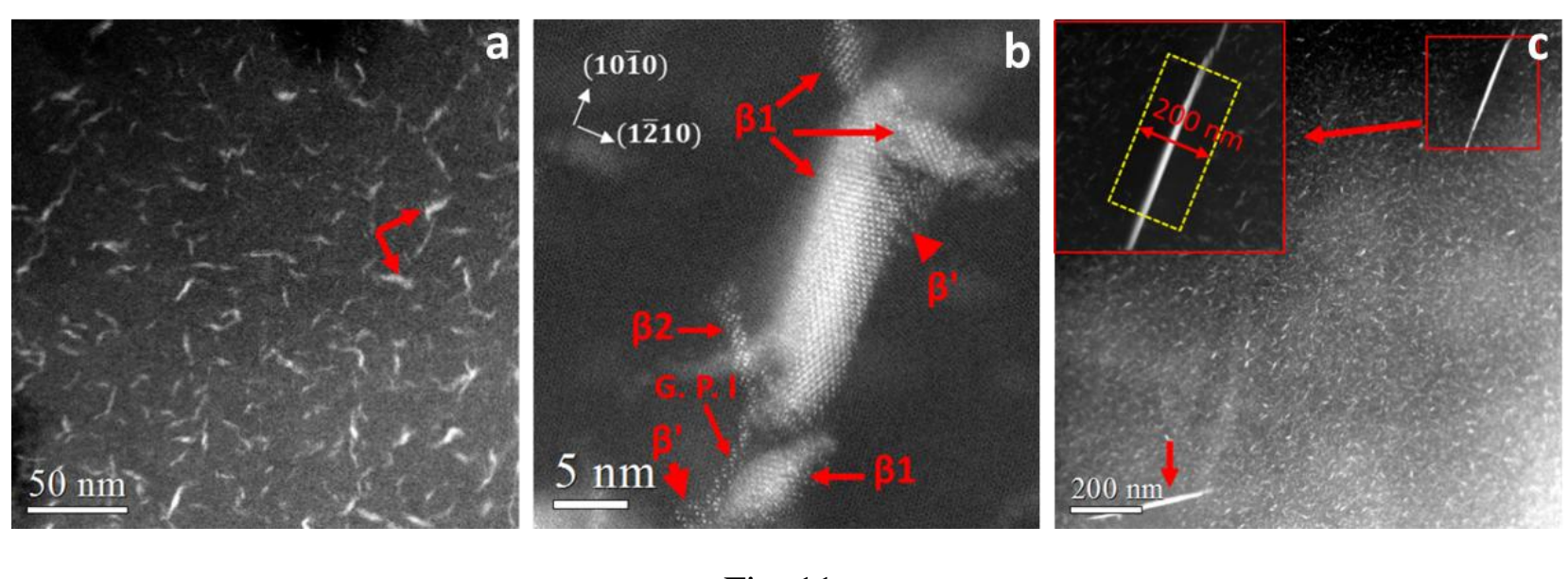

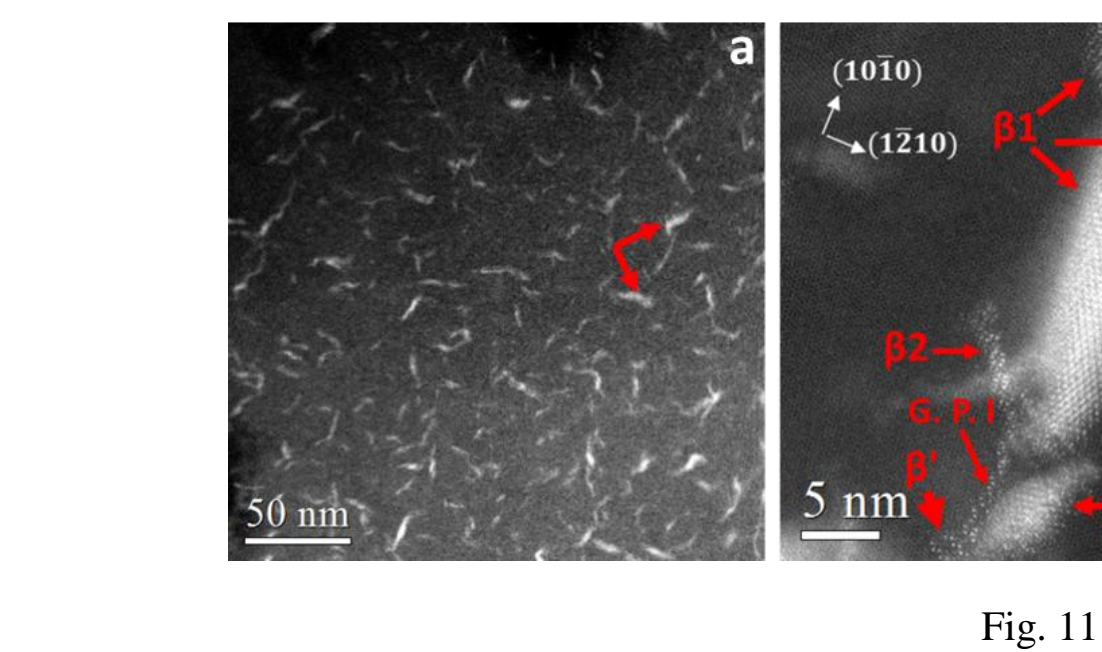
.

.

\section{.

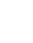

.



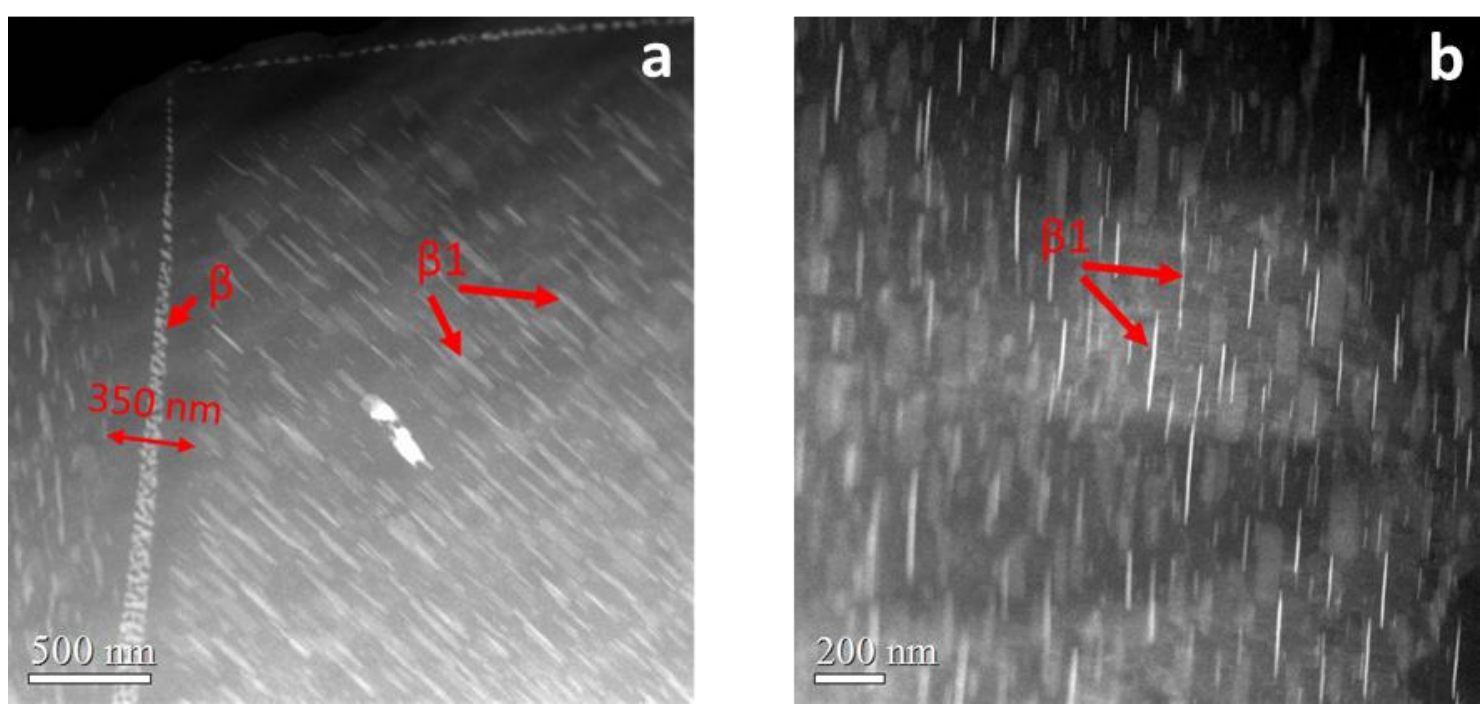

Fig. 12

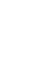

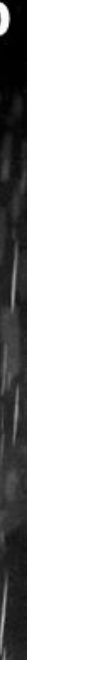

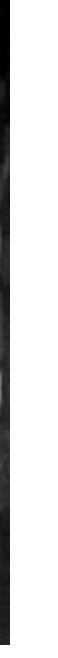

.
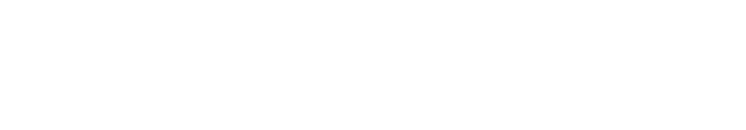

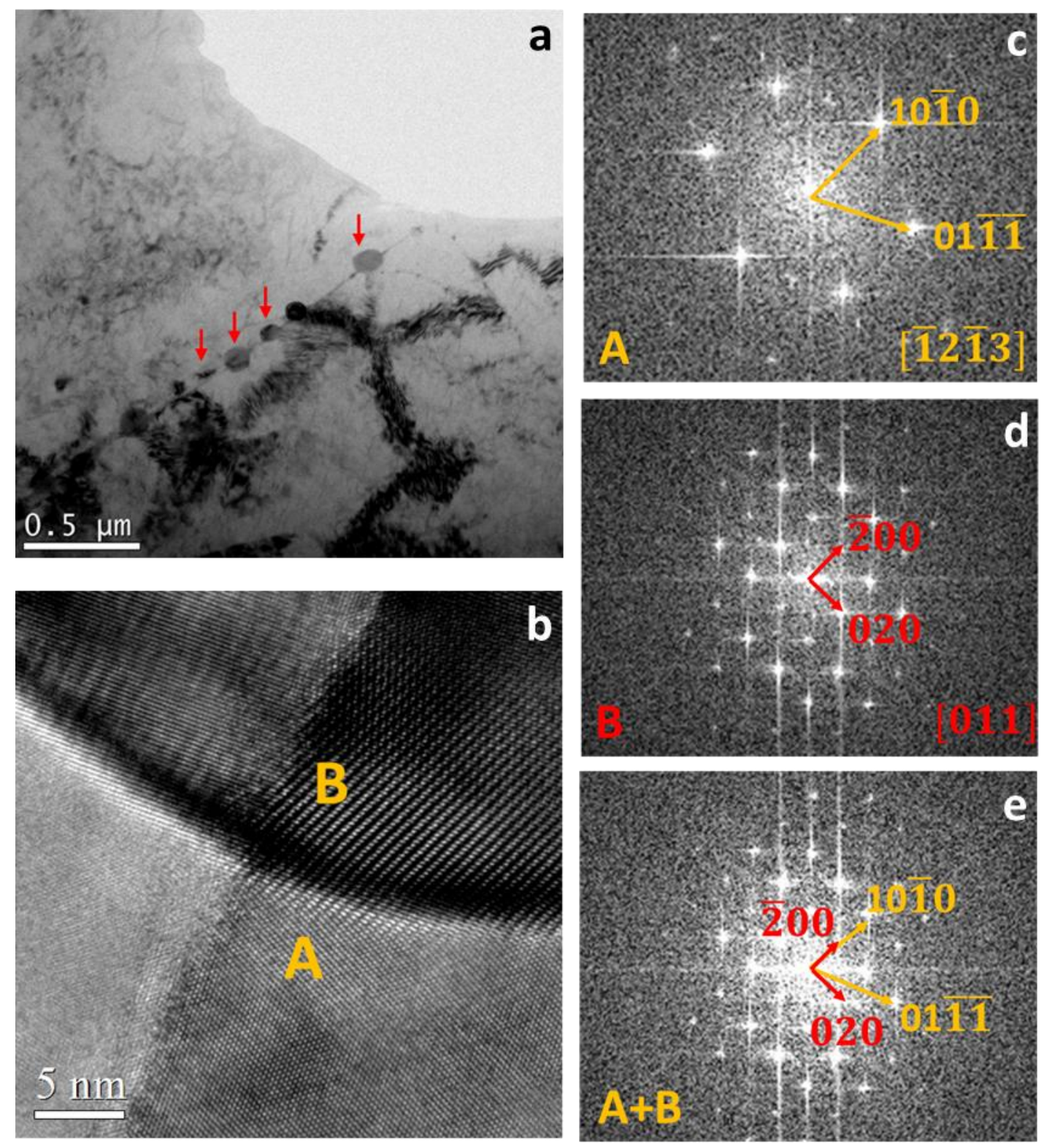

Fig. 13 

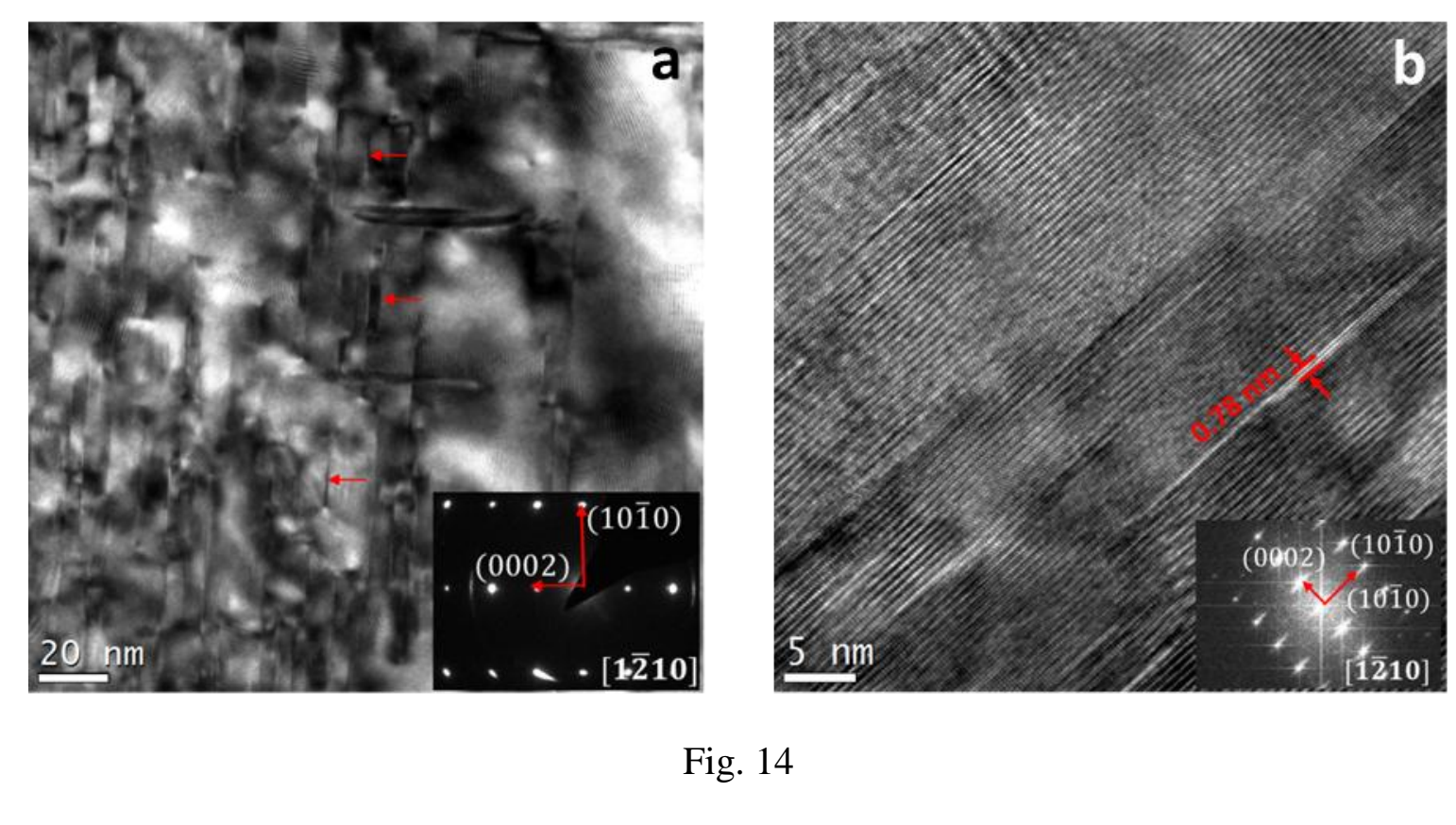

Figure 14$$
\text { nm }
$$

210]

.

.

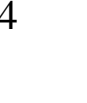

(n)

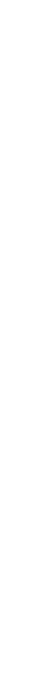

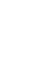

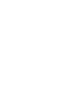


Table 1. Summary of the microstructure analysis and precipitation sequence performed on $\mathrm{Mg}-3 \mathrm{Nd}-0.2 \mathrm{Zn}$ samples aged at $200^{\circ} \mathrm{C}$.

\begin{tabular}{|c|c|c|c|c|c|c|}
\hline \multirow[t]{3}{*}{ Seq. } & \multirow[t]{3}{*}{ Phase } & \multirow[t]{3}{*}{ Structure/Lattice parameters/Composition } & \multicolumn{4}{|l|}{ Kinetics at $200{ }^{\circ} \mathrm{C}$} \\
\hline & & & \multirow[t]{2}{*}{ Qualitative } & \multicolumn{3}{|c|}{ Quantitative $\left(\mathbf{N}_{\mathrm{v}} \times 10^{5} \mathrm{~nm}^{-3}\right)^{\dagger}$} \\
\hline & & & & $2 \mathrm{hr}$ & $8 \mathrm{hr}$ & $64 \mathrm{hr}$ \\
\hline 1 & $\begin{array}{l}\text { Clusters }(N d- \\
\mathrm{Zn})\end{array}$ & - & $\begin{array}{l}\text { In abundance in some regions of } \\
\text { under-aged alloy }(2 \mathrm{hr})\end{array}$ & $\begin{array}{l}113.2 \pm 27.6^{*} \\
95.6 \pm 33\end{array}$ & - & - \\
\hline \multirow[t]{3}{*}{2} & G. P. zones I & $D 019 / a_{p p t}=2 a_{M g} ; c_{p p t}=c_{M g} / M g_{3}(N d, Z n)$ & $\begin{array}{l}\text { Abundant after } 2 \mathrm{hr} \text {; Less abundant } \\
\text { after8hr }\end{array}$ & $8.95 \pm 1.5$ & $1.59 \pm 1.13$ & - \\
\hline & G. P. zones II & $\begin{array}{l}\text { Orthorhombic/a } a_{\beta^{\prime}}=2 a_{M g} ; b_{\beta^{\prime}}=2 \sqrt{3} \mathrm{aMg} \\
c_{\beta}=c_{M g} / M g_{7}(N d, \mathrm{Zn})\end{array}$ & $\begin{array}{l}\text { Less abundant after } 2 \mathrm{hr} \text {, Sparse } \\
\text { distribution after } 8 \mathrm{hr}\end{array}$ & $3.22 \pm 1.51$ & 0.4 & - \\
\hline & G. P. zones III & $\begin{array}{l}\text { Orthorhombic/ } a_{\beta 2}=2 a_{M g} ; b_{\beta 2}=\sqrt{3} a M g ; c_{\beta 2}=c_{M g} / \\
M g_{3}(N d, Z n)\end{array}$ & $\begin{array}{l}\text { Less abundant after } 2 \mathrm{hr} \text {, Sparse } \\
\text { distribution after } 8 \mathrm{hr}\end{array}$ & $6.27 \pm 1.25$ & $0.6 \pm 0.28$ & - \\
\hline 3 & $\beta^{\prime}$ & $\begin{array}{l}\text { Orthorhombic/ } a_{\beta^{\prime}}=2 a_{M g} ; b_{\beta^{\prime}}=2 \sqrt{3} a M g \\
c_{\beta}=c_{M g} / M g_{7}(N d, Z n)\end{array}$ & $\begin{array}{l}\text { Small concentration after } 2 \mathrm{hr} \\
\text { Abundant after } 8 \mathrm{hr}\end{array}$ & $<0.9$ & $1.2 \pm 0.25$ & - \\
\hline 4 & $\beta_{2}$ & $\begin{array}{l}\text { Orthorhombic/ } a_{\beta 2}=2 a_{M g} ; b_{\beta 2}=\sqrt{3} a M g ; c_{\beta 2}=c_{M g} / \\
M g_{3}(\mathrm{Nd}, \mathrm{Zn})\end{array}$ & $\begin{array}{l}\text { Small concentration after } 2 \mathrm{hr} \text {; less } \\
\text { abundant after } 8 \mathrm{hr}\end{array}$ & $<0.9$ & 1.59 & - \\
\hline 5 & $\beta_{1}$ & $\begin{array}{l}B C T / \mathrm{a}_{\beta 1}=0.52 \mathrm{~nm} ; \mathrm{b}_{\beta 1}=0.52 \mathrm{~nm} ; \mathrm{c}_{\beta 1}=0.74 \mathrm{~nm} / \\
M g_{3}(\mathrm{Nd} / \mathrm{Zn})\end{array}$ & $\begin{array}{l}\text { Sparse distribution after } 2 \mathrm{hr} \text {; Abundant } \\
\text { after } 8 \mathrm{hr} \text {, dominant after } 64 \mathrm{hr}\end{array}$ & $<0.1$ & $2 \pm 0.56$ & $0.32 \pm 0.07$ \\
\hline 6 & $\gamma^{\prime}$ & $\begin{array}{l}\text { y' ordered } H C P / \mathrm{a}_{\gamma}=0.321 \mathrm{~nm} ; \mathrm{c}_{\gamma}=0.781 \mathrm{~nm} / \\
\operatorname{Mg}_{0.7}\left(\mathrm{Gd}_{0.15} \mathrm{Zn}_{0.15}\right)\end{array}$ & $\begin{array}{l}\text { Uneven distribution in a few grains } \\
\text { after } 64 \mathrm{hr}\end{array}$ & - & - & - \\
\hline 7 & $\beta$ & $F C C / \mathrm{a}_{\beta},=1.11 \mathrm{~nm} / \mathrm{Mg}_{12}(\mathrm{Nd}, \mathrm{Zn})$ & Along grain boundaries after $64 \mathrm{hr}$ & - & - & - \\
\hline
\end{tabular}

$\dagger$ The values are based on quantitative analysis on HREM-STEM images of the sample aged for $2 \mathrm{hr}$ at $200{ }^{\circ} \mathrm{C}$.

* The value is obtained from APT analysis of clusters of the sample aged for $2 \mathrm{hr}$ at $200{ }^{\circ} \mathrm{C}$. 